\title{
An experimental rat model of sporadic Alzheimer's disease and rescue of cognitive impairment with a neurotrophic peptide
}

\author{
Silvia Bolognin, \\ Department of Neurochemistry, New York State Institute for Basic Research in Developmental \\ Disabilities, 1050 Forest Hill Road, Staten Island, NY 10314, USA \\ Julie Blanchard, \\ Department of Neurochemistry, New York State Institute for Basic Research in Developmental \\ Disabilities, 1050 Forest Hill Road, Staten Island, NY 10314, USA
}

\section{Xiaochuan Wang,}

Department of Neurochemistry, New York State Institute for Basic Research in Developmental Disabilities, 1050 Forest Hill Road, Staten Island, NY 10314, USA

\section{Gustavo Basurto-Islas,}

Department of Neurochemistry, New York State Institute for Basic Research in Developmental Disabilities, 1050 Forest Hill Road, Staten Island, NY 10314, USA

\section{Yunn Chyn Tung,}

Department of Neurochemistry, New York State Institute for Basic Research in Developmental Disabilities, 1050 Forest Hill Road, Staten Island, NY 10314, USA

\section{Erik Kohlbrenner,}

Department of Gene and Cell Medicine, Mount Sinai School of Medicine, New York, NY, USA

Inge Grundke-Iqbal, and

Department of Neurochemistry, New York State Institute for Basic Research in Developmental Disabilities, 1050 Forest Hill Road, Staten Island, NY 10314, USA

\section{Khalid Iqbal}

Department of Neurochemistry, New York State Institute for Basic Research in Developmental Disabilities, 1050 Forest Hill Road, Staten Island, NY 10314, USA

\section{Abstract}

\begin{abstract}
Alzheimer's disease (AD) is multifactorial and, to date, no single cause of the sporadic form of this disease, which accounts for over $99 \%$ of the cases, has been established. In AD brain, protein phosphatase-2A (PP2A) activity is known to be compromised due to the cleavage and translocation of its potent endogenous inhibitor, $\mathrm{I}_{2}^{\mathrm{PP} 2 \mathrm{~A}}$, from the neuronal nucleus to the cytoplasm. Here, we show that adeno-associated virus vector-induced expression of the Nterminal $\mathrm{I}_{2 \mathrm{NTF}}$ and $\mathrm{C}$-terminal $\mathrm{I}_{2 \mathrm{CTF}}$ halves of $\mathrm{I}_{2}^{\mathrm{PP} 2 \mathrm{~A}}$, also called SET, in brain reproduced key features of $\mathrm{AD}$ in Wistar rats. The $\mathrm{I}_{2 \mathrm{NTF}-\mathrm{CTF}}$ rats showed a decrease in brain PP2A activity, abnormal hyperphosphorylation and aggregation of tau, a loss of neuronal plasticity and impairment in spatial reference and working memories. To test whether early pharmacologic intervention with a neurotrophic molecule could rescue neurodegeneration and behavioral deficits,
\end{abstract}


2.5-month-old $\mathrm{I}_{2 \mathrm{NTF}-\mathrm{CTF}}$ rats and control littermates were treated for 40 days with Peptide 6 , an 11-mer peptide corresponding to an active region of the ciliary neurotrophic factor. Peripheral administration of Peptide 6 rescued neurodegeneration and cognitive deficit in $\mathrm{I}_{2 \mathrm{NTF}-\mathrm{CTF}}$ animals by increasing dentate gyrus neurogenesis and mRNA level of brain derived neurotrophic factor. Moreover, Peptide 6-treated $\mathrm{I}_{2 \mathrm{NTF}-\mathrm{CTF}}$ rats showed a significant increase in dendritic and synaptic density as reflected by increased expression of synapsin I, synaptophysin and MAP2, especially in the pyramidal neurons of $\mathrm{CA} 1$ and $\mathrm{CA} 3$ of the hippocampus.

\section{Introduction}

Alzheimer's disease (AD) is the most common cause of dementia in the elderly. It is histopathologically characterized by two lesions: intracellular neurofibrillary tangles (NFTs) of filaments made from hyperphosphorylated tau protein [15], and extracellular senile plaques containing predominantly $\beta$-amyloid peptide $(A \beta)$. Early observations identified the accumulation of $A \beta$ into plaques as the main trigger for the wide neurodegeneration characterizing this disorder [10, 17]. Lately, evidence has indicated that early-stage $A \beta$ aggregates, oligomers, may be more relevant to $\mathrm{AD}$ etiology and may better correlate with the severity of dementia than plaques [42]. Nevertheless, the failure of $A \beta$-based therapies in treating $\mathrm{AD}$ has driven the scientific community to explore other targets such as tau protein $[6,11,49]$. Despite being a relatively specific hallmark of $A D, A \beta$ accumulation might not be solely responsible for initiating the neurodegenerative process. As a matter of fact, Oddo et al. [44] reported that reduction of soluble $A \beta$ and tau levels, but not $A \beta$ alone, improved cognitive performance in a $3 \mathrm{xTg}-\mathrm{AD}$ mouse model of $\mathrm{AD}$.

The dysfunction affecting the microtubule-associated protein tau consists of an abnormal increase of phosphorylation levels. In normal physiological conditions tau contains 2-3 molecules of phosphate per molecule of the protein. In AD brain tau contains 5-9 moles of phosphate/mole of protein [28]. Protein phosphatase-2A (PP2A) is a major regulator of tau phosphorylation in the brain. Both mRNA and protein levels of PP2A have been found to be decreased in $\mathrm{AD}$ brain $[52,63]$ while the level of its inhibitor $2\left(\mathrm{I}_{2}^{\mathrm{PP} 2 \mathrm{~A}}\right)$, also known as SET, is increased [58]. $\mathrm{I}_{2}^{\mathrm{PP} 2 \mathrm{~A}}$ is widely expressed in different tissues and localizes primarily in the nucleus, where it mainly protects histones from acetylation [51]. We previously reported that $\mathrm{I}_{2}^{\mathrm{PP} 2 \mathrm{~A}}$ is cleaved into an N-terminal fragment $\left(\mathrm{I}_{2 \mathrm{NTF}}\right)$ and a C-terminal fragment $\left(\mathrm{I}_{2 \mathrm{CTF}}\right)$ and it translocates from neuronal nucleus to cytoplasm in affected areas of AD brain [58]. Moreover, in vivo expression of $\mathrm{I}_{2 \mathrm{CTF}}$ in the brain resulted in neurodegeneration associated with abnormal hyperphosphorylation and aggregation of tau and intraneuronal accumulation of $A \beta$ as well as with spatial reference memory impairment in rats [66]. Targeting abnormal hyperphosphorylation of tau protein through activation of PP2A has thus been proposed as a potential therapeutic option for $\mathrm{AD}[25,64]$. An alternative approach may involve the promotion of synaptic formation and modulation of synaptic connectivity using neurotrophic factors [47, 59]. However, attempts to use neurotrophic factors as an effective tool to counteract AD symptoms have been inconclusive. This was mainly due to the lack of effective delivery systems and to the appearance of several side effects, such as weight loss. The use of small growth factor-based peptides which can exploit neurotrophic factor mechanisms to decrease the selective loss of neuronal population without the limitations mentioned above could thus represent a valuable approach.

We have previously reported that peripheral administration of a blood-brain barrierpermeable 11-mer peptide, named Peptide 6, corresponding to an active region of ciliary neurotrophic factor (CNTF), $\mathrm{CNTF}_{146-156}$, was able to restore cognition in a transgenic animal model of $\mathrm{AD}$, the $3 \mathrm{xTg}-\mathrm{AD}$ mouse, by increasing neuronal plasticity [4]. 
Furthermore, Peptide 6 was able to increase the number of proliferating hippocampal neuronal progenitor cells into neurons in adult mice [5]. CNTF, a member of the interleukin- 6 cytokine family, has been shown to enhance neurogenesis in the hippocampus [71] and to promote self-renewal and maintenance of neuronal precursor cells in vitro [21]. In vivo, CNTF has been reported to activate a Janus kinase/signal transducer and activator of a transcription-mediated survival pathway that prevents synaptic and neuronal degeneration [8].

In this study, we employed an adeno-associated virus serotype 1 (AAV1) vector to express $\mathrm{I}_{2 \mathrm{NTF}}$ and $\mathrm{I}_{2 \mathrm{CTF}}$ by intracerebroventricularly infecting the newborn rats. At 4 months of age the $\mathrm{I}_{2 \mathrm{NTF}-\mathrm{CTF}}$ transduced animals were characterized by a dramatic decrease in brain PP2A activity resulting in synaptic loss, moderate $\mathrm{A} \beta$ and tau accumulation and marked behavioral impairments. At 13 months of age $\mathrm{I}_{2 \mathrm{NTF}-\mathrm{CTF}}$ rats showed a significant abnormal hyperphosphorylation and aggregation of tau and intraneuronal $\mathrm{A} \beta$. Treatment of the $\sim 2.5$ month-old $\mathrm{I}_{2 \mathrm{NTF}-\mathrm{CTF}}$ rats for 40 days with Peptide 6 reversed synaptic and cognitive deficits without any apparent side effects on general behavior of the animals.

\section{Materials and methods}

\section{Study outline}

On the day of birth ( $p 0.5$ ) male Wistar rat pups were anesthetized on ice, and $2 \mu 1$ containing $4 \times 10^{9}$ AAV1 genomic equivalents of $\mathrm{I}_{2 \mathrm{NTF}-\mathrm{CTF}}$ or, as a control, AAV1-green fluorescent protein (GFP) were injected into each lateral ventricle of the brain with a 10- $\mu 1$ Hamilton syringe (Hamilton Syringe Company, Reno, NV, USA). After 2.5 months, both groups of animals were treated for 40 days with Peptide 6 (intraperitoneal injection daily; $400 \mathrm{nmol} / \mathrm{kg} /$ day) or vehicle $(\mathrm{NaCl}, 0.9 \%)$. Peptide 6 , which resembles the active region of human CNTF (residues 146-156), was synthesized by solid phase peptide synthesis (SPPS) method $[3,5]$. After 18 days of the treatment for 3 consecutive days, rats were injected with $\mathrm{BrdU}(50 \mathrm{mg} / \mathrm{kg} / \mathrm{dose})$ to label dividing cells. At the end of the treatment, the effect of longterm overexpression of $\mathrm{I}_{2 \mathrm{NTF}-\mathrm{CTF}}$ as well as administration of Peptide 6 were tested on cognitive deficits, tau phosphorylation, $A \beta$ level, neurogenesis and neuronal plasticity. Abnormal hyperphosphorylation and aggregation of tau and $\mathrm{A} \beta$ immunohistochemical staining were also studied 13 months post-AAV1-I 2 NTF-CTF transduction.

\section{Construction of the recombinant plasmids and vector packing}

Previously generated $p E G F P-N 3 / I_{2}^{\mathrm{PP} 2 \mathrm{~A}}[61]$ was used as a template to generate by PCR $\mathrm{I}_{2 \mathrm{CTF}}$ and $\mathrm{I}_{2 \mathrm{NTF}} \mathrm{cDNA}$. The primers were: forward $5^{\prime}$-gatggatccaaagccagcaggaaga- $3^{\prime}$ and reverse $5^{\prime}$-gatctcgagttagtcatcttctc- $3^{\prime}$ for $\mathrm{I}_{2 \mathrm{CTF}}$, forward $5^{\prime}$-attactagtatgtcggcgecggcggcc- $3^{\prime}$ and reverse $5^{\prime}$-tgcgatatc ttaattctgcgtttgactcgaacg- $3^{\prime}$ for $\mathrm{I}_{2 \mathrm{NTF}}$. The plasmid was verified by DNA sequencing. The cDNA fragments were then cloned into the multicloning site of the AAV viral genome containing plasmid pTRUF12 and expression was driven by the CMV promoter/enhancer. Serotype 1 virus was generated and titers were calculated from standard curve generated from pTRUF as previously described $[20,66,76]$.

\section{Animal housing and intracerebroventricular (ICV) injection}

Wistar rats were housed and bred according to the PHS Policy on Human Care and Use of Laboratory animals (revised March 15, 2010). Rats were housed (2/3 animals per cage) with a 12:12-h light/dark cycle and with ad libitum access to food and water. Studies on animals were carried out according to approved protocols from our Institutional Animal Care and Use Committee. 
For immunohistochemistry and biochemical analyses, animals were anesthetized with an overdose of sodium pentobarbital $(125 \mathrm{mg} / \mathrm{kg}$ ) and then killed by transcardial perfusion with $0.1 \mathrm{M}$ phosphate buffered saline (PBS). The left hemisphere was dissected into hippocampus, cerebral cortex (parietal associated and motor cortex and hind limb region), and ventricular area and kept at $-80^{\circ} \mathrm{C}$ for biochemical analysis while the right half of the brain was immersion-fixed for $48 \mathrm{~h}$ in $4 \%$ paraformaldehyde in PBS, then cryoprotected in $30 \%$ sucrose for immunohistochemical investigations and $40 \mu \mathrm{m}$ sagittal sections were cut using a freezing-sliding Microtome.

\section{Reverse-transcriptase PCR (rt-PCR) and quantitative real-time PCR (RT-qPCR)}

Total RNA was extracted from cerebral cortex, hippocampus and ventricular area with RNeasy plus mini kit (Qiagen, Valencia, CA, USA) according to manufacturer's instructions. cDNA synthesis was achieved using Super script first strand kit (Invitrogen, Carlsbad, CA, USA). rt-PCR amplification was performed in a thermocycler for 30 cycles (a cycle consisted of steps with denaturation for $30 \mathrm{~s}$ at $95^{\circ} \mathrm{C}$, annealing for $30 \mathrm{~s}$ at $60^{\circ} \mathrm{C}$, polymerization for $30 \mathrm{~s}$ at $72^{\circ} \mathrm{C}$ ). The primer sequence for $\mathrm{I}_{2 \mathrm{NTF}}$ was the following: forward $5^{\prime}$-gcaagaagcgattgaacaca- $3^{\prime}$ and reverse $5^{\prime}$-gcagtgcctcttcatcttcc- $3^{\prime}$. The amplification products were resolved on $2 \%$ agarose gels and quantified using the Molecular Imager system (Bio-Rad, Hercules, CA, USA).

RT- $q$ PCR was performed using Brilliant SYBR Green Master Mix (Agilent, Santa Clara, CA, USA) in a Stratagene Mc3000p PCR detection system under the following conditions: $10 \mathrm{~min}$ at $95^{\circ} \mathrm{C}, 40$ cycles of denaturation at $95^{\circ} \mathrm{C}$ for $30 \mathrm{~s}$, annealing $55^{\circ} \mathrm{C}$ for $1 \mathrm{~min}$, extension at $72^{\circ} \mathrm{C}$ for $1 \mathrm{~min}$. The primer sequences were the following: forward $5^{\prime}$-gcgg cagataaaaagactgc- $3^{\prime}$ and reverse $5^{\prime}$-gccagccaattctctttttg- $3^{\prime}$ for brain derived neurotrophic factor (BDNF); forward $5^{\prime}$-tgttgctgccaagaaagatg- $3^{\prime}$ and reverse $5^{\prime}$-acgtggctggactca atacc- $3^{\prime}$ for microtubule-associated protein 2 (MAP2); forward $5^{\prime}$-tgtcagggaactggaagacc- $3^{\prime}$ and reverse $5^{\prime}$-agttccac gatgagctgctt- $3^{\prime}$ for synapsin I; forward $5^{\prime}$-aaggtgacctccaagtgtgg- $3^{\prime}$ and reverse $5^{\prime}$ - acgatttctgctccatggtc- $3^{\prime}$ for tau; forward $5^{\prime}$-gggaggtggaaggaaaagag- $3^{\prime}$ and reverse $5^{\prime}$ - cettcttggtcaccaccact- $3^{\prime}$ for neurofilament $\mathrm{M}$; forward $5^{\prime}$-cgccetgtgagctgaactctg- $3^{\prime}$ and reverse $5^{\prime}$-ctgcttctcagctgcctgacc- $3^{\prime}$ for tropomyosin receptor kinase B (TrkB); forward $5^{\prime}$ gacatgccgectggagaaac- $3^{\prime}$ and reverse $5^{\prime}$-agcccaggatgccctttagt- $3^{\prime}$ for glyceraldehyde 3 phosphate dehydrogenase (GAPDH). Relative quantification was performed using the $\Delta \Delta C_{\mathrm{t}}$ method.

\section{Protein phosphatase-2A (PP2A) activity assay}

PP2A activity was assayed by ELISA in rat hippocampus homogenate (in the presence or absence of $15 \mathrm{nM}$ okadaic acid) [66].

\section{Sarkosyl-insoluble tau}

Sarkosyl-insoluble tau was isolated from the cerebral cortices of 13 -month-old $\mathrm{I}_{2 \mathrm{NTF}} \mathrm{CTF}$ and GFP control rats according to Greenberg and Davies [14]. The sarkosyl-soluble and the sarkosyl-insoluble fractions were dissolved in Laemmli sample buffer and employed for Western blots.

\section{Western blots}

Rat hippocampus was homogenized to generate $10 \%(\mathrm{w} / \mathrm{v})$ homogenate in cold buffer containing $50 \mathrm{mM}$ Tris- $\mathrm{HCl}$ (pH 7.4), 8.5\% sucrose, 2 mM EDTA, 2 mM EGTA, $10 \mathrm{mM} \beta$ mercaptoethanol, benzamidine $5 \mathrm{mM}, 0.5 \mathrm{mM}$ AEBSF, $4 \mu \mathrm{g} / \mathrm{ml}$ pepstatin A and $10 \mu \mathrm{g} / \mathrm{ml}$ each of aprotinin and leupeptin, $20 \mathrm{mM} \beta$-glycerolphosphate, $100 \mathrm{mM}$ sodium fluoride, 1 $\mathrm{mM}$ sodium vanadate and $100 \mathrm{nM}$ okadaic acid. After protein assay by modified Lowry 
method [2], Western blots were carried out and quantitated as described previously [66]. The following primary antibodies were used: anti-GluR1 (1:1,000; Millipore, Temecula, CA, USA), anti-GluR2/3 (1:5,000; Abcam, Cambridge, MA, USA), anti-PSD95 (1:1,000; Cell Signaling Technology, Danvers, MA, USA), anti-Egr-1 (1:400; Santa Cruz Biotechnology, Santa Cruz, CA, USA), anti-GAPDH (1:1,000; Invitrogen, Carlsbad, CA, USA), anti-PP2Ac (1:1,000; BD Transduction Laboratories, KY, USA), pan-tau antibody 92e (1:5,000; [16], tau pS199 (1:1,000; Biosource, Camarillo, CA, USA), tau pT205 (1:1,000; Biosource), tau pS214 (1:1,000; Biosource), tau pT217 (1:1,000; Biosource), M4 to tau phosphorylated Thr231/Ser235 (1:500; [18], tau pS262 (1:1,000; Biosource), tau pS396 (1:1,000; Biosource), pS422 (1:1,000; [57], and PHF1 [14].

\section{Immunohistochemistry}

Immunohistochemistry was performed on free-floating sections and every sixth brain section was chosen for densitometry and quantification. The primary antibodies against the following proteins were used at the indicated dilution: rabbit polyclonal anti-tau pS199, pT205, pS262, and pS396 (1:200; Biosource), anti-synapsin I (1:2,000; Stressgen, Victoria, BC, Canada), anti-synaptophysin (1:200; Millipore, Temecula, CA, USA), anti-MAP2a,b (1:1,000; Sternberger Monoclonals, MD, USA), anti-BrdU (1:400; Accurate, Westbury, NY,

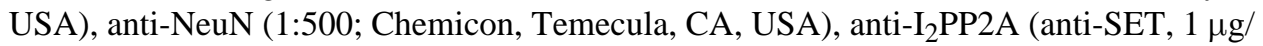
$\mathrm{ml}$; [66], rabbit polyclonal anti-A $\beta_{1-40}(5 \mu \mathrm{g} / \mathrm{ml}$; Abcam, Cambridge, MA, USA; 1:200; Invitrogen, Camarillo, CA, USA), anti- $N$-methyl $\mathrm{D}$-aspartate (NMDA) receptor 1 (1:200; ThermoScientific, Rockford, IL, USA). Alexa 488-conjugated goat anti-mouse IgG antibody (1:500; Molecular Probes, Carlsbad, CA, USA), Alexa 594-conjugated goat anti-rabbit IgG antibody (1:500; Molecular Probes, Carlsbad, CA, USA), Alexa 555 conjugated goat antirabbit IgG (1:500; Invitrogen, Camarillo, CA, USA), and Cy5-conjugated goat anti-mouse (1:500; Jackson Laboratory, Maine, USA) were used as secondary antibodies.

Nissl staining was performed on floating sections to evaluate neuronal loss. The sections were stained with $0.1 \%$ Cresyl violet (w/v) (Sigma-Aldrich, St. Louis, MO, USA) and were examined with light microscopy.

BrdU immunohistochemistry was performed unmasking BrdU antigen by incubating tissue sections for $2 \mathrm{~h}$ in $50 \%$ formamide in $0.03 \mathrm{M}$ sodium citrate and $0.3 \mathrm{M} \mathrm{NaCl}$ at $65^{\circ} \mathrm{C}$, followed by $5 \mathrm{~min}$ wash in $0.03 \mathrm{M}$ sodium citrate and $0.3 \mathrm{M} \mathrm{NaCl}$ and subsequent incubation for $30 \mathrm{~min}$ at $37^{\circ} \mathrm{C}$.

\section{Densitometry and Stereology}

Densitometry of immunohistochemical staining and counting the number of BrdUimmunoreactive (BrdU-IR) cells were performed as described previously [4, 67].

\section{Behavioral tests}

Open field-Anxiety and exploratory activities were evaluated allowing rats to freely explore an open field for $20 \mathrm{~min}$. The testing apparatus was a classic open field (i.e., a PVC square arena of $100 \times 100 \mathrm{~cm}$, with $70 \mathrm{~cm}$ high walls). The open field was placed in a part of the room separated from the experimentator and the control station with a black opaque curtain. Rats were individually submitted to a single 20 -min session. Since for rodents the middle of a non-familiar arena is anxiogenic, anxiety was studied analyzing the percentage of time spent in the middle of the arena. To assess exploratory activity, the total distance the animals covered in the arena was tracked and measured. Data collection was performed using tracking files of the experiment recorded with SMART (Pan Lab/San Diego Instruments) version 2.0.14 software. 
Water-maze spatial reference memory task-Spatial reference learning and memory were evaluated in the water maze using a procedure adapted from that previously described by Morris and collaborators [40]. The test requires that rats use a spatial navigational strategy based on a spatial representation of the environment to find a fixed submerged escape platform. The procedure was performed in a $180-\mathrm{cm}$ diameter circular tank. The pool was filled with water $\left(21^{\circ} \mathrm{C} \pm 1\right)$ made opaque by adding white non-toxic paint. Acquisition started with the escape platform ( $14 \mathrm{~cm}$ diameter submerged $1 \mathrm{~cm}$ below water surface) in the Northwest quadrant and each animal was given $90 \mathrm{~s}$ to find the platform. If the rat did not find the platform in $90 \mathrm{~s}$, it was gently guided to it. At the end of each trial the rat was left on the platform for $20 \mathrm{~s}$ then dried and returned to its home cage until the next trial. Four such acquisition trials were given on each day for three consecutive days. A test for retention (i.e., a probe trial) was given 5 days after the last day of training. During the probe trial the rat was allowed to swim in the tank without the escape platform for $60 \mathrm{~s}$. The measures of learning were the time and the distance swum to reach the escape platform. For the probe trial, the tank was divided into four imaginary quadrants and a small zone where the escape platform had been during the training. The measures of the probe trial were the percentage of time spent and the percentage of distance covered in the target quadrant. Rat behavior in the water maze was monitored by a Samsung Digital Camera (SDC 4304) mounted to the ceiling and tracked and timed by a SMART (Pan Lab/San Diego Instruments) version 2.0.14 software.

Working memory task-This task occurred in the same spatial environment as the spatial reference memory task because the achievement of this task required that animals mastered the spatial environment. The testing procedure used was similar to the spatial reference task except that the platform location changed every day. Moreover, the inter-trial intervals (ITIs) varied across days. On day 1 the ITI was $30 \mathrm{~s}$, on day 2 it was $15 \mathrm{~min}$ and on day 3 it was $2 \mathrm{~h}$. Time and distance to reach the escape platform were recorded.

\section{Statistical analysis}

Data were analyzed with STATVIEW and GraphPad software and are presented as mean \pm SEM for behavioral evaluations and \pm SD for all the other studies. Multiple comparisons among groups were performed using ANOVA, followed by Tukey's or Fisher's post hoc test. For all other comparisons (including inter-group comparisons), Student's $t$ test was used. * $p$ $<0.05 ; * * p<0.01$.

\section{Results}

\section{AAV-mediated expression of $\mathrm{I}_{\mathbf{2 N T F}}$ and $\mathrm{I}_{\mathbf{2}} \mathrm{CTF}$}

It has been previously reported that the use of AAV1-mediated gene transfer can be a useful approach to achieve stable expression of specific transgenes [30]. To verify if the expression of $\mathrm{I}_{2 \mathrm{NTF}-\mathrm{CTF}}$ in rat brain can be an etiological factor leading to the development of AD-like pathology in vivo, we bilaterally injected in the lateral ventricles of $p 0.5$ Wistar rats AAV1 virus encoding $\mathrm{I}_{2 \mathrm{NTF}}$ and $\mathrm{I}_{2 \mathrm{CTF}}$ or, as a control, GFP (Fig. 1a-c). Using primers targeting $\mathrm{I}_{2 \mathrm{NTF}}$ sequence, rt-PCR of brain homogenate showed the expression of the virus encoded $\mathrm{I}_{2 \mathrm{NTF}-\mathrm{CTF}}$ transgene. Interestingly, transgene delivery spread from the site of injection, namely the ventricular area, to the hippocampus and cerebral cortex and it was stable since it could be observed 4 months post-infection in the animals (Fig. 1d). As expected, GFP rats did not show infection of $\mathrm{I}_{2 \mathrm{NTF}}$, proving that AAV vectors successfully determined infection of the desired transgene. In addition, we investigated $\mathrm{I}_{2 \mathrm{CTF}}$ expression and localization by immunohistochemistry using anti-SET antibody which recognizes $\mathrm{I}_{2}^{\mathrm{PP} 2 \mathrm{~A}}$ full length and its fragment $\mathrm{I}_{2 \mathrm{CTF}}$. Consistent with previous reports, we observed a predominantly nuclear 
staining of $\mathrm{I}_{2}^{\mathrm{PP} 2 \mathrm{~A}}$ with very limited staining in the cytoplasm and neurites $[36,46]$ in the different brain areas of GFP rats (Fig. 1e-h). On the contrary, I INTF-CTF infected rats showed a positive staining in the cytoplasm suggesting that the transgene was expressed (Fig. 1e-h). Quantification of fluorescence intensity revealed a significant increased of immunoreactivity in CA1 (Fig. 1e; Student $t$ test, $p=0.022$ ) and CA3 (Fig. 1f; Student $t$ test, $p=0.027$ ) of the hippocampus and in ventricular area (Fig. 1g; Student $t$ test, $p=0.021$ ) of $\mathrm{I}_{2 \mathrm{NTF}-\mathrm{CTF}}$ compared to GFP rats. The same trend was observed in the cortex even though it did not reach statistical significance, probably due to low signal to background ratio (Fig. $1 \mathrm{~h}$; Student $t$ test, $p=0.252$ ).

\section{$\mathrm{I}_{2 \mathrm{NTF}-\mathrm{CTF}}$ induces abnormal hyperphosphorylation and aggregation of tau and intraneuronal $A \beta$}

$\mathrm{I}_{2}^{\mathrm{PP} 2 \mathrm{~A}}$ is about $20 \%$ upregulated and is cleaved into $\mathrm{I}_{2 \mathrm{NTF}}$ and $\mathrm{I}_{2 \mathrm{CTF}}$, and translocated from the neuronal nucleus to the cytoplasm in $\mathrm{AD}$ brain [58]. To determine whether these $\mathrm{I}_{2}^{\mathrm{PP} 2 \mathrm{~A}}$ changes could have been responsible for $\mathrm{AD}$ characteristic tau and any $\mathrm{A} \beta$ changes, we studied abnormal hyperphosphorylation and aggregation of tau and intraneuronal $\mathrm{A} \beta$ in 13month-old $\mathrm{I}_{2 \mathrm{NTF}-\mathrm{CTF}}$ and -GFP control rats. We selected to investigate phosphorylation of tau at Ser199, Thr205, Ser262, and Ser396, which are among the major AD abnormal hyperphosphorylation sites and are known to be regulated by PP2A [12, 33, 65]. We found abnormal hyperphosphorylation of tau at all these four sites studied in the CA3 and CA1 areas of the hippocampus and in the cerebral cortex in $\mathrm{I}_{2 \mathrm{NTF}-\mathrm{CTF}}$ rats (Fig. 2a). The immunostaining with anti-pT205 and anti-pS262 were more intense than with anti-pS199 and anti-pS396 in CA1 than in CA3 and cerebral cortex, and vice versa with the latter two antibodies. The exact reasons for these different region-specific immunostaining patterns remain to be investigated. Higher accessibility of pS199 and pS396 than pT205 and pS262 sites to the antibodies, different levels of transduction in different brain regions, inhibition of PP2A, the activities of tau kinases that are regulated by PP2A in different brain regions, could be among the involved factors. The 13-month-old GFP rats showed low levels of phosphorylation at pT205 and pS262, especially in the CA1 areas, all of which were markedly increased in $\mathrm{I}_{2 \mathrm{NTF}-\mathrm{CTF}}$ rats. Furthermore, we found a marked shift from sarkosylsoluble to -insoluble tau (Fig. 2b) and in its abnormal hyperphosphorylation (ptau/total tau) in $\mathrm{I}_{2 \mathrm{NTF}-\mathrm{CTF}}$ rats (Fig. 2c). The $\mathrm{I}_{2 \mathrm{NTF}-\mathrm{CTF}}$ rats showed intraneuronal $\mathrm{A} \beta$ both in the area of the lateral ventricle and in the cerebral cortex (Fig. 2d). Thus, a $\sim 20 \%$ increase in the expression of $\mathrm{I}_{2 \mathrm{NTF}-\mathrm{CTF}}$ (Fig. 1e-h) in rat brain by 13 months of age showed early tau and $\mathrm{A} \beta$ changes.

\section{$\mathrm{I}_{2 \mathrm{NTF}-\mathrm{CTF}}$ expression induced a decrease in PP2A activity and an increase in A $\boldsymbol{\beta}_{1-40}$ and tau levels, and synaptic loss in 4-month-old rats}

In $\mathrm{AD}$ brain, tau and $\mathrm{A} \beta$ pathologies are associated with an unsuccessful neurogenesis and loss of neuronal plasticity [26]. To determine whether a shifting of the balance from neurodegeneration to regeneration of the brain by enhancing neurogenesis and neuronal plasticity at early stages of the disease can rescue cognitive impairment, we chose to study the levels of the inhibition of PP2A activity, tau and A $\beta$ changes and neuronal plasticity in 4-month-old $\mathrm{I}_{2 \mathrm{NTF}-\mathrm{CTF}}$ rats (Fig. 3).

Previously, $\mathrm{I}_{2}^{\mathrm{PP} 2 \mathrm{~A}}$ isolated from bovine kidney was identified as a potent inhibitor of PP2A [32]. In the present study, we found that PP2A activity was dramatically reduced in the hippocampus of 4-month-old $\mathrm{I}_{2 \mathrm{NTF}-\mathrm{CTF}}$ rats compared to the control animals (Fig. 3a, Student $t$ test, $p=0.003$ ). Nevertheless, Western blot analysis revealed that expression of $\mathrm{I}_{2 \mathrm{NTF}-\mathrm{CTF}}$ had no significant effect on the level of PP2Ac catalytic subunit (Fig. 3b, Student $t$ test, $p=0.077)$. 
Concomitant with the decrease in PP2A activity we found an immunohistochemical increase in intraneuronal $\mathrm{A} \beta_{1-40}$ in the parietal association cortex of $\mathrm{I}_{2 \mathrm{NTF}-\mathrm{CTF}}$ rats (Fig. 3c, d, Student $t$ test, $p=0.032$ ) while no significant changes were detected in other brain regions including the hippocampus (data not shown). This finding is consistent with $A D$ where $A \beta$ pathology in the cerebral cortex is known to precede that in the hippocampus. However, whether $\mathrm{I}_{2 \mathrm{NTF}-\mathrm{CTF}}$ rats in old age will develop any extracellular $\mathrm{A} \beta$ plaques remains to be studied.

Since PP2A has a key role in regulating tau phosphor-ylation and it accounts for $70 \%$ of total tau phosphatase activity in the brain [33], we sought to investigate by Western blots whether tau phosphorylation at disease-relevant sites was affected. Representative immunoblots of hippocampal homogenate developed with the pan tau antibody 92e and normalized against GAPDH staining showed that tau level was significantly increased in $\mathrm{I}_{2 \mathrm{NTF}-\mathrm{CTF}}$ compared to GFP rats (Fig. 3e, Student $t$ test, $p=0.012$ ). On the other hand, though there was a consistent trend for hyperphosphorylation of tau at pSer199, pThr205, pSer214, pThr217, pThr231-pSer235, pSer396, pSer396-pSer404 and pSer422 when normalized against total tau (Fig. 3e), these differences did not reach statistical significance in the 4-month-old $\mathrm{I}_{2 \mathrm{NTF}-\mathrm{CTF}}$ rats.

Besides $\mathrm{A} \beta$ and tau pathologies, $\mathrm{AD}$ is characterized by neurodegeneration that is associated with decreased neuronal plasticity. We, therefore, investigated whether $\mathrm{I}_{2 \mathrm{NTF}-\mathrm{CTF}}$ infection induced neurodegeneration producing loss of synaptic and dendritic plasticity. Nissl staining revealed no apparent changes in the neuronal cytoarchitecture in the hippocampus of $\mathrm{I}_{2 \mathrm{NTF}-\mathrm{CTF}}$ as compared to control animals (Fig. 3f). Semi-quantitative immunohistochemical data showed a statistical significant decrease of fluorescent intensity of synapsin I, a synaptic vesicle-associated phosphoprotein implicated in the regulation of synaptic strength, in CA3 of the hippocampus in $\mathrm{I}_{2 \mathrm{NTF}-\mathrm{CTF}}$ rats (Fig. $3 \mathrm{~g}$, Student $t$ test, $p=0.015$ ). Similarly, quantification of mRNA levels of the dendritic marker MAP2 by RT- $q$ PCR showed that MAP2 transcript was decreased in the cerebral cortex of $\mathrm{I}_{2 \mathrm{NTF}-\mathrm{CTF}}$ compared to AVV-GFP (Fig. 3h, Student $t$ test, $p=0.049$ ).

TrkB has been recognized as a potent regulator of synaptic plasticity of the hippocampus as well as of other brain regions [41]. Notably, TrkB-deficient mice showed impairment of long-term potentiation (LTP) [39, 69]. We, therefore, investigated the mRNA expression of TrkB receptor in the cerebral cortex of $\mathrm{I}_{2 \mathrm{NTF}-\mathrm{CTF}}$ and control rats and found a decrease in the former (Fig. 3i, Student $t$ test, $p=0.018$ ). The studies on 4-month-old $\mathrm{I}_{2 \mathrm{NTF}-\mathrm{CTF}}$ rats showed these animals at early stages of the AD-like changes.

\section{Increase in neurogenesis and BDNF activation by Peptide 6}

Since we generated the $\mathrm{I}_{2 \mathrm{NTF}-\mathrm{CTF}}$ rat model based on the findings in sporadic AD, and this animal model, as described above, faithfully reproduced several key features of the human disease, we next investigated whether Peptide 6, which is neurogenic and neurotrophic, can alleviate the neurodegeneration caused by $\mathrm{I}_{2 \mathrm{NTF}-\mathrm{CTF}}$. We treated 2.5 -month-old $\mathrm{I}_{2 \mathrm{NTF}-\mathrm{CTF}}$ and GFP-infected rats with Peptide 6 or vehicle for 7 weeks. The role of newborn hippocampal neurons is still partially unknown but several studies suggest their involvement in processing spatial memory and LTP [7, 9]. Adult neurogenesis occurs primarily in two brain regions: the subventricular zone and the subgranular zone (SGZ) of the DG [74]. We observed that BrdU-positive cells were predominantly localized in the inner granular cell layer (iGCL) at the border of the GCL and the hilus. Analysis of the number of positive cells, using unbiased stereological approaches, revealed significant differences among groups in the number of BrdU-positive cells in the SGZ of the DG (Fig. 4a-e, ANOVA, $p=$ 0.034). A marked increase in the number of BrdU-positive cells was found in GFP rats treated with Peptide 6 compared to vehicle-treated animals (Fisher's post hoc test, $p=$ 
0.007). Interestingly, Peptide 6 significantly increased the number of BrdU-positive cells also in $\mathrm{I}_{2 \mathrm{NTF}-\mathrm{CTF}}$ compared to vehicle-treated $\mathrm{I}_{2 \mathrm{NTF}-\mathrm{CTF}}$ rats (Fisher's post hoc test, $p=$ 0.050). Differentiation of newborn cells was assessed measuring the co-localization of the mature neuronal marker, NeuN, with the BrdU-IR cells. We observed a significant difference among groups (Fig. 4f, ANOVA, $p=0.019$ ). Treatment with Peptide 6 significantly increased the number of NeuN-BrdU-IR cells in $\mathrm{I}_{2 \mathrm{NTF}-\mathrm{CTF}}$ compared to the vehicle-treated control animals (Student $t$ test, $p=0.005$ ).

Since the survival of newborn neurons has been shown to require BDNF signaling [48] and BDNF is a regulator of axonal outgrowth, we studied whether chronic Peptide 6 treatment can activate BDNF pathway. Quantification of mRNA level of BDNF in the parietal association cortex using RT- $q$ PCR showed differences between groups (Fig. 4g, ANOVA, $p$ $=0.029)$. In particular, treatment with Peptide 6 increased BDNF transcription in GFP (Student $t$ test, $p=0.005$ ) as well as in $\mathrm{I}_{2 \mathrm{NTF}-\mathrm{CTF}}$ (Student $t$ test, $p=0.036$ ) rats compared to untreated controls. The expression of BDNF mRNA in $\mathrm{I}_{2 \mathrm{NTF}-\mathrm{CTF}}$ rats was decreased compared to the other groups even though it did not reach statistical significance (Student $t$ test, $p=0.053)$. The decrease in mRNA level of TrkB receptor in $\mathrm{I}_{2 \mathrm{NTF}-\mathrm{CTF}}$ rats was attenuated on treatment with Peptide 6 (Fig. 4h).

\section{Activation of glutamate receptors by Peptide 6}

Synaptic pruning is a feature of AD pathology. We thus evaluated the expression of AMPA receptor subunits due to their essential role for synaptic transmission and LTP as well as cellular mechanisms which are connected with learning and memory [37]. Peptide 6 was able to induce a significant increase of the GluR1 subunit of AMPA receptors in the hippocampi of GFP compared to GFP treated with vehicle (Fig. 5a, Student $t$ test, $p=$ 0.009). In addition, GluR2/3 expression was significantly higher in the hippocampus of Peptide 6-treated $\mathrm{I}_{2 \mathrm{NTF}-\mathrm{CTF}}$ than the vehicle-treated GFP rats (Fig. 5a Student $t$ test, $p=$ 0.001 ) whereas no significant differences among groups were observed in the level of PSD95 (Fig. 5a, ANOVA, $p=0.23$ ). Immunohistochemical investigation in the DG confirmed the same pattern highlighting a specific increase in the immunoreactivity for GluR2/3 in $\mathrm{I}_{2 \mathrm{NTF}-\mathrm{CTF}}$ rats treated with Peptide 6 compared to the vehicle-treated animals (Fig. 5b, Student $t$ test, $p=0.033$ ). Immunohistochemical staining revealed a decrease in the density of the NMDA receptor subunit NR1-positive neurons in the CA1 (Fig. 5c, ANOVA, $p=0.016$ ) and in the CA3 (Fig. $5 \mathrm{~d}$, ANOVA, $p=0.026$ ) of the hippocampus in $\mathrm{I}_{2 \mathrm{NTF}-\mathrm{CTF}}$ rats. Peptide 6 administration enhanced the expression of NR1 in CA3 and CA1 in GFP but not the $\mathrm{I}_{2 \mathrm{NTF}-\mathrm{CTF}}$ rats.

We next examined the protein expression of Egr-1, an immediate-early response gene, a marker of the activation of neuronal circuits. We found a significant difference among groups (Fig. 5e, ANOVA, $p=0.0005$ ) and in particular increased expression of Egr-1 in GFP (Student $t$ test, $p=0.018$ ) and $\mathrm{I}_{2 \mathrm{NTF}-\mathrm{CTF}}$ (Student $t$ test, $p=0.012$ ) rats after Peptide 6 treatment.

\section{Peptide 6 enhances synaptic and neuritic density}

Employing antibodies directed to specific presynaptic structures, we assessed whether Peptide 6 could rescue synaptic loss in the brains of $\mathrm{I}_{2 \mathrm{NTF}-\mathrm{CTF}}$ rats. Immunohistochemical studies showed that Peptide 6 significantly increased the expression of synapsin I in the CA1 (Fig. 6a, Fisher's post hoc, $p=0.041$ ) and CA3 (Fig. 6b, Fisher's post hoc, $p=0.043$ ) of the hippocampus and in the parietal association cortex (Fig. 6c, Fisher's post hoc, $p=0.047$ ) of $\mathrm{I}_{2 \mathrm{NTF}-\mathrm{CTF}}$ compared to vehicle-treated rats. It is worth noting that the significant loss in the expression of this protein in the CA3 of $\mathrm{I}_{2 \mathrm{NTF}-\mathrm{CTF}}$ rats compared to GFP was completely reversed after Peptide 6 treatment. In addition, Peptide 6 increased synaptophysin level in 
the CA3 (Fig. 6d; Student $t$ test, $p=0.018$ ) and MAP2 level in the CA1 (Fig. 6e, ANOVA, p $=0.004$; Fisher's post hoc, $p=0.019$ ) of $\mathrm{I}_{2 \mathrm{NTF}-\mathrm{CTF}}$ rats. Both MAP2 immunoreactivity (Fig. $6 \mathrm{e}$, Fisher's post hoc, $p=0.004$ ) and mRNA (Fig. 6f, Student $t$ test, $p=0.047$ ) were increased in $\mathrm{I}_{2 \mathrm{NTF}-\mathrm{CTF}}$ rats treated with Peptide 6. Synapsin I mRNA level in the cerebral cortex showed differences among groups (Fig. 6g, ANOVA, $p=0.036$ ), which was reduced in $\mathrm{I}_{2 \mathrm{NTF}-\mathrm{CTF}}$ rats compared to GFP (Fig. 6g, Student $t$ test, $p=0.048$ ) and it was rescued by Peptide 6 (Student $t$ test, $p=0.024$ ). Peptide 6 administration increased the mRNA level of Neurofilament M in $\mathrm{I}_{2 \mathrm{NTF}-\mathrm{CTF}}$ (Fig. 6h, Student $t$ test, $p=0.022$ ) as well as GFP (Student $t$ test, $p=0.030$ ) rats compared to vehicle-treated animals. Moreover, the mRNA level of tau was increased in $\mathrm{I}_{2 \mathrm{NTF}-\mathrm{CTF}}$ treated with Peptide 6 compared to the vehicle-treated $\mathrm{I}_{2 \mathrm{NTF}-\mathrm{CTF}}$ (Fig. 6i, ANOVA, $p=0.036$; Student $t$ test, $p=0.049$ ) or GFP rats (Student $t$ test, $p=0.040$ ). These data support the remodeling and enhancement of neuronal architecture by Peptide 6 treatment. Collectively, these results suggest an altered molecular composition of the pre-synaptic machinery, especially within the CA3 area in the hippocampus of $\mathrm{I}_{2 \mathrm{NTF}-\mathrm{CTF}}$ rats which was rescued by Peptide 6 .

\section{Effect of Peptide 6 on $A \beta$ and tau changes in INTF-CTF rats}

Although Peptide 6, as shown above, works as a neurotrophin, nevertheless we investigated whether it had any effect on $A \beta$ and tau changes in $\mathrm{I}_{2 \mathrm{NTF}-\mathrm{CTF}}$ rats. While Peptide 6 did not have any significant effect on $A \beta$ accumulation, as determined by immunohistochemical staining (figure not shown), it increased the tau mRNA level (Fig. 6i) but caused no significant changes in the hyperphosphorylation of tau at several $\mathrm{AD}$ abnormal sites studied (figure not shown). The lack of any significant effect of Peptide 6 on A $\beta$ and abnormal hyperphosphorylation of tau in the present study is consistent with our previous similar observations in 3xTg-AD transgenic mice treated with the peptide at early stages of the pathology [4].

\section{Rescue of cognitive impairment by Peptide 6 in $\mathrm{I}_{2 \mathrm{NTF}-\mathrm{CTF}}$ rats}

During the period of the treatment the condition of individual animals was assessed every week by evaluating physical state and grooming. We did not observe any alteration in general physical state including grooming and posture, either in the $\mathrm{I}_{2 \mathrm{NTF}-\mathrm{CTF}}$ rats treated with Peptide 6 or vehicle. Evaluation of reflexes and muscle strength using the clasping reflex (Fig. 7a, ANOVA, $p=0.697$ ) and prehensile traction test (Fig. 7b, ANOVA, $p=$ 0.405 ) did not reveal any significant differences between groups. Assessment of anxiety and exploration in the open field did not reveal any significant difference among groups. All animals spent similar time in the center of the arena (Fig. 7c, ANOVA, $p=0.267$ ) and covered similar distance within the open field (Fig. 7d, ANOVA, $p=0.657$ ). These results showed that neither expression of $\mathrm{I}_{2 \mathrm{NTF}-\mathrm{CTF}}$ nor treatment with Peptide 6 induced any modification of general behavior. This suggests that treatment with Peptide 6 did not provoke any side effects.

Spatial reference memory task-Cognitive evaluation focused on testing the hippocampal function since it is the first structure affected in Alzheimer disease and it is the key structure for memory processing. We tested the animals for a spatial reference memory task, followed by a spatial working memory task in the same experimental environment.

We first analyzed the swim speed of the animals. Statistical analysis did not reveal any difference among groups (Fig. 7e, ANOVA, $p=0.555$ ). Therefore, results of the training were analyzed as latency to reach the submerged platform in the water maze. During the training of the task, I $_{2 \mathrm{NTF}-\mathrm{CTF}}$ rats displayed delayed performance compared to GFP groups (Fig. 7f, ANOVA, $p=0.063$; Fisher's post hoc test, $p<0.025$ ). This finding showed that AAV-I ${ }_{2 N T F-C T F}$ rats were impaired in the learning of the task compared to GFP rats, but 
that treatment with Peptide 6 rescued this impairment. Global average performance during training clearly showed the impairment of $\mathrm{I}_{2 \mathrm{NTF}-\mathrm{CTF}}$ compared to GFP rats treated with vehicle (Fig. 7g, Student $t$ test, $p=0.045$ ) or Peptide 6 (Student $t$ test, $p=0.037$ ), and that treatment with Peptide 6 increased I $2 \mathrm{NTF}-\mathrm{CTF}$ rats' performance compared to GFP animals' levels (ANOVA, $p=0.040$ ). Statistical analyses of the probe trial, showed that $\mathrm{I}_{2 \mathrm{NTF}-\mathrm{CTF}}$ rats visited significantly less the target quadrant than $\mathrm{I}_{2 \mathrm{NTF}-\mathrm{CTF}}$ rats treated with Peptide 6 (Fig. 7h, Student $t$ test, $p=0.007$ ). $\mathrm{I}_{2 \mathrm{NTF}-\mathrm{CTF}}$ rats treated with Peptide 6 spent similar time in the target quadrant compared to GFP groups (Student $t$ test, $p>0.122$ ). These results confirmed the impairment of $\mathrm{I}_{2 \mathrm{NTF}-\mathrm{CTF}}$ rats to encode and memorize spatial information, i.e. spatial coordinates of the submerged platform and that treatment with Peptide 6 reduced spatial impairment.

Working memory-The working memory of the animals was tested in the same water maze and experimental environment as above for the spatial reference task. The escape latency to find the submerged platform at inter-trial-intervals (ITI) was $30 \mathrm{~s}$ on day 1, 15 min on day 2 , and $2 \mathrm{~h}$ on day 3 . Statistical analyses did not show any difference among groups when the ITI was $30 \mathrm{~s}$ or $15 \mathrm{~min}$ (Fig. 7i, ANOVA, $p=0.617$; Fig. 7j, ANOVA, $p=$ $0.558)$. But, when the ITI increased to $2 \mathrm{~h}, \mathrm{I}_{2 \mathrm{NTF}-\mathrm{CTF}}$ rats treated with vehicle displayed longer escape latencies than other groups (Fig. 7k, ANOVA, $p=0.002$, Fisher's post hoc test, $p<0.007$ ), and $\mathrm{I}_{2 \mathrm{NTF}-\mathrm{CTF}}$ rats treated with Peptide 6 presented similar performance as GFP rats (Fisher's post hoc test, $p>0.419$ ). These results showed that $\mathrm{I}_{2 \mathrm{NTF}-\mathrm{CTF}}$ rats displayed working memory impairment for long delays of retention but that treatment with Peptide 6 alleviated this deficit.

\section{Discussion}

Despite the fact that the sporadic form of AD accounts for over $99 \%$ of the cases, to date, most of the experimental animal models are based on the familial form of the disease and are overexpression transgenic mice. AD is multifactorial and development of rational therapeutic drugs will require understanding of various etiopathogenic mechanisms of this disease. PP2A, which is the major regulator of tau phosphorylation, is down-regulated in AD brain [13]. A cause of decreased PP2A activity is the overexpression and cleavage and translocation of its inhibitor, $\mathrm{I}_{2}^{\mathrm{PP} 2 \mathrm{~A}}$ from the neuronal nucleus to the cytoplasm [58]. The present study shows that the expression of the $\mathrm{I}_{2}^{\mathrm{PP} 2 \mathrm{~A}}$ cleavage products, $\mathrm{I}_{2 \mathrm{NTF}}$ and $\mathrm{I}_{2 \mathrm{CTF}}$, in the brain reproduces several histopathological features and cognitive impairment in rat, yielding a disease-relevant animal model of sporadic AD. A transgenic truncated tau overexpression rat model was previously reported to show extensive tau pathology, primarily in the brain stem, and motor dysfunction in the absence of any $A \beta$ accumulation [75].

Aging is the biggest known risk factor for AD. Even in carriers of the disease-causing mutations of APP, presenilin 1 and presenilin 2, the disease onset is mostly in the fifth or sixth decade of life. It is possible that the brain's regenerative capacity is slowly, progressively compromised with age and becomes insufficient to negate the specific disease pathogenesis. The present study shows that chronic treatment with Peptide 6 can enhance neurogenesis and neuronal plasticity, and can rescue cognitive impairment in $\mathrm{I}_{2 \mathrm{NTF}-\mathrm{CTF}}$ rats.

In an attempt to evaluate the contribution of $\mathrm{I}_{2}^{\mathrm{PP} 2 \mathrm{~A}}$ cleavage to the cognitive deficit and major features observed in AD, we employed virally mediated gene transfer of both $\mathrm{I}_{2 \mathrm{NTF}}$ and $\mathrm{I}_{2 \mathrm{CTF}}$. One of the major advantages of this approach, compared to the use of transgenic animals, is that long-term transgene expression is achieved without affecting the genetic 
background of the animal [30]. Rats injected with AAV serotype 1 vector encoding the two fragments of $\mathrm{I}_{2}^{\mathrm{PP} 2 \mathrm{~A}}$ showed a marked reduction of PP2A activity.

Although in $\mathrm{I}_{2 \mathrm{NTF}-\mathrm{CTF}}$ rat hippocampus the reduction of PP2A activity was successfully achieved, the evidence of infection was provided by rt-PCR and immunohistochemistry; the level of expression was too low to be detected by Western blots. It is worth noting that a small amount of the inhibitor was sufficient to achieve a significant reduction in PP2A activity and the consequent neurodegeneration and cognitive impairment in $\mathrm{I}_{2 \mathrm{NTF}-\mathrm{CTF}}$ rats.

Reduction of PP2A activity affects APP regulation [23,34], contributing to A $\beta$ production as shown by the increased expression of $A \beta_{1-40}$ in the cerebral cortex. As is the case in human $\mathrm{AD}$ and $3 \mathrm{xTg}-\mathrm{AD}$ mice [43], we found $\mathrm{A} \beta$ alterations in the absence of a pronounced alteration of tau phosphorylation in $~ 4-$ month-old animals. Indeed, in 3xTg-AD mice, tau pathology becomes apparent only between 12 and 15 months of age and staining with PHF1 antibody, a marker of late stage of tau pathology, is evident only at 18 months of age. While we found a marked increase in abnormal hyperphosphorylation and aggregation of tau in 13month-old $\mathrm{I}_{2 \mathrm{NTF}-\mathrm{CTF}}$ rats, at 4 months of age these animals showed an increase in the total tau level. Even at this early stage, practically all this increase in tau was in the form of the hyperphosphorylated protein. Interestingly, by 13 months in $\mathrm{I}_{2 \mathrm{NTF}-\mathrm{CTF}}$ rats the level of total tau was decreased. This is similar to what was reported in 8-month AAV1- I $_{2}$ CTF rats previously [66] and probably represents loss of axonal plasticity. The intraneuronal $A \beta$ was more evident in 13-month-old as compared to the 4-month-old $\mathrm{I}_{2 \mathrm{NTF}-\mathrm{CTF}}$ rats. A recent report has suggested that intraneuronal A $\beta$ is most likely APP [68]. However, several major $\mathrm{A} \beta$ research groups in the field disagree on this issue (see http://www.alzforum.org).

In this study, we thus presented a model in which AAV1-induced expression of $\mathrm{I}_{2 \mathrm{NTF}}$ and $\mathrm{I}_{2 \mathrm{CTF}}$ resulted in decreased activity of PP2A coupled with a significant increase in abnormal hyperphosphorylation and aggregation of tau and intraneuronal accumulation of $A \beta$ at 13 months of age. I $_{2 \mathrm{NTF}-\mathrm{CTF}}$ rats at 4 months of age developed a clinical phenotype that included spatial and working memory impairments as they were not able to encode and store spatial representation of the environment and coordinates of the submerged platform.

Moreover, $\mathrm{I}_{2 \mathrm{NTF}} \mathrm{CTF}$ expression led to neurodegeneration and loss of dendritic and synaptic plasticity. This suggests that synaptic alteration is one of the earliest neurodegenerative consequences of PP2A-reduced activity. Remarkably, impairment of synaptic plasticity has been recognized as a key early event in the pathogenesis of $\mathrm{AD}[1,50]$ which consequently affects synaptic remodeling and LTP. Interestingly, several reports suggested that alteration of hippocampal synaptic plasticity precedes extracellular plaque deposition and neuronal loss [60]. Likewise, synaptic pathology has been detected as earliest manifestation of the disease before the formation of neurofibrillary tangles or marked tau hyperphosphorylation in P301S tau transgenic mice [72]. In addition, early studies supported a link between the degree of cognitive decline in AD patients and changes in the levels of presynaptic markers [55]. Remarkably, synapsin I is associated with axogenesis and synaptogenesis and decreased mRNA and protein levels of this presynaptic marker in $\mathrm{I}_{2 \mathrm{NTF}-\mathrm{CTF}}$ compared to GFP rats observed in the present study probably contributed to the impairment in spatial and working memory.

In this regard, the present study supports the use of neurotrophic-based peptides to rescue synaptic and behavioral dysfunction. Molecules able to enhance synaptogenesis and neuronal plasticity may increase the resistance to the clinical manifestation of the pathology, thereby delaying the onset of clinical expression [54]. Neurodegenerative disorders may indeed affect neurotrophic factor functions, reducing adaptation of neurons to diseaserelated alterations. Notably, unlike the parent molecule, Peptide 6 administration showed neurotrophic properties without inducing adverse effects. Furthermore, the efficacy of 
peripheral administration at nanomolar level and the capability to penetrate the blood-brain barrier render Peptide 6 a promising pharmacological strategy.

Here, we provide strong evidence that Peptide 6 increased mRNA level of the BDNF receptor, TrkB, a potent presynaptic activator. Several reports have indeed demonstrated that $\mathrm{BDNF} / \mathrm{TrkB}$ signaling can modulate synaptic function, increasing levels of pre-synaptic proteins $[62,70,73]$ and dendritic branching [56]. In the present study the increase in BDNF mRNA upon treatment with Peptide 6 is consistent with the increased expression of the dendritic marker MAP2 and synaptic markers synapsin I and synaptophysin. The increase of endogenous BDNF levels in the brain of Peptide 6-treated animals represents an important finding as BDNF mRNA levels have been found to be diminished in AD brain [22, 45]. Since cholinergic neurons are stimulated by BDNF, reduced availability of this factor could trigger degeneration of this neuronal population [19]. Moreover, BDNF knockout mice showed reduced LTP [29], suggesting that BDNF might play an important role in neuroplasticity connected with learning and memory [35]. Thus, activation of TrkB receptor initiates complex signaling pathways that modify synaptic structure and function [24]. The increased mRNA level of tau and neurofilament $\mathrm{M}$ as well as stimulation of the early response gene Egr-1 in the present study suggest that, beside potentiating BDNF-induced transmitter release, Peptide 6 heightened synaptic outgrowth. On the other hand, in I $_{2 \text { NTF-CTF }}$ rats, Peptide 6 did not alter the level of PSD-95 and NMDA receptor (NR1) suggesting that it exerts its effect primarily up-regulating vesicle-associated synaptic proteins. Nevertheless, we cannot rule out that longer treatment of the $\mathrm{I}_{2 \mathrm{NTF}-\mathrm{CTF}}$ rats can have a significant beneficiary effect of the Peptide on the post-synaptic machinery. As a matter effect, post-synaptic AMPA receptor subunits GluR1 and GluR 2/3 were increased due to Peptide 6 treatment.

We postulate that the behavioral rescue in cognition may be, besides increase in neuronal plasticity, due also to Peptide 6-mediated enhancement in the expression of newborn hippocampal neurons as shown by the increase of BrdU incorporation. Several neurodegenerative disorders, including $\mathrm{AD}$, have been shown to have impaired neurogenesis $[31,53]$. As newborn neurons are incorporated in the DG network, they improve DG plastic properties by facilitating the expression of LTP and the encoding of novel information [38]. Thus, modulation of hippocampal neurogenesis represents an important goal as newborn neurons can be recruited into new memory networks [27].

In summary, these and our previous studies $[58,66]$ strongly support the possibility that reduced activity of PP2A due to enhanced cleavage of its inhibitor $\mathrm{I}_{2}^{\mathrm{PP} 2 \mathrm{~A}}$ probably represents an etiopathogenic mechanism of $\mathrm{AD}$. By demonstrating loss of synaptic integrity we provide strong evidence implicating synaptic pathology as an early neurotoxic consequence of expression of $\mathrm{I}_{2 \mathrm{NTF}-\mathrm{CTF}}$ resulting in marked cognitive impairment. AAV-I ${ }_{2 \mathrm{NTF}-\mathrm{CTF}}$ virus delivered locally to the brain can be used effectively to obtain an early stage model of sporadic AD. Furthermore, peripheral administration of Peptide 6 represents a valuable tool to reverse hippocampal function deficits, rescuing the short-term capability to encode and remember new information in association with the stimulation of neurogenesis, dendritic and synaptic plasticity without affecting tau and $\mathrm{A} \beta$ changes.

\section{Acknowledgments}

We are most grateful to Dr. Aurelian Radu for his help in the design of the AAV1-I2NTF-CTF constructs, Dr. George Merz for his help in confocal microscopy, Drs. Ezzat El-Akkad and Jianhua Shi for their help in the preparation of the figures, and Ms. Janet Murphy for secretarial assistance. Studies described in this paper were supported in part by the New York State Office of People with Developmental Disabilities, NIH/NIA grant AG019158, and a research grant from EVER NeuroPharma, Unterach, Austria. 


\section{References}

1. Arendt T. Synaptic degeneration in Alzheimer's disease. Acta Neuropathol. 2009; 118:167-179. [PubMed: 19390859]

2. Bensadoun A, Weinstein D. Assay of proteins in the presence of interfering materials. Anal Biochem. 1976; 70:241-250. [PubMed: 1259145]

3. Blanchard J, Chohan MO, Li B, Liu F, Iqbal K, Grundke-Iqbal I. Beneficial effect of a CNTF tetrapeptide on adult hippo-campal neurogenesis, neuronal plasticity, and spatial memory in mice. J Alzheimers Dis. 2010; 21:1185-1195. [PubMed: 20952820]

4. Blanchard J, Wanka L, Tung YC, et al. Pharmacologic reversal of neurogenic and neuroplastic abnormalities and cognitive impairments without affecting Abeta and tau pathologies in $3 \times \mathrm{Tg}-\mathrm{AD}$ mice. Acta Neuropathol. 2010; 120:605-621. [PubMed: 20697724]

5. Chohan MO, Li B, Blanchard J, et al. Enhancement of dentate gyrus neurogenesis, dendritic and synaptic plasticity and memory by a neurotrophic peptide. Neurobiol Aging. 2011; 32:1420-1434. [PubMed: 19767127]

6. de Barreda EG, Avila J. Is tau a suitable therapeutical target in tauopathies? World J Biol Chem. 2010; 1:81-84. [PubMed: 21540993]

7. Deng W, Aimone JB, Gage FH. New neurons and new memories: how does adult hippocampal neurogenesis affect learning and memory? Nat Rev Neurosci. 2010; 11:339-350. [PubMed: 20354534]

8. Garcia P, Youssef I, Utvik JK, et al. Ciliary neurotrophic factor cell-based delivery prevents synaptic impairment and improves memory in mouse models of Alzheimer's disease. J Neurosci. 2010; 30:7516-7527. [PubMed: 20519526]

9. Ge S, Yang CH, Hsu KS, Ming GL, Song H. A critical period for enhanced synaptic plasticity in newly generated neurons of the adult brain. Neuron. 2007; 54:559-566. [PubMed: 17521569]

10. Glenner GG, Wong CW. Alzheimer's disease: initial report of the purification and characterization of a novel cerebrovascular amyloid protein. Biochem Biophys Res Commun. 1984; 120:885-890. [PubMed: 6375662]

11. Golde TE, Schneider LS, Koo EH. Anti-abeta therapeutics in Alzheimer's disease: the need for a paradigm shift. Neuron. 2011; 69:203-213. [PubMed: 21262461]

12. Gong CX, Lidsky T, Wegiel J, Zuck L, Grundke-Iqbal I, Iqbal K. Phosphorylation of microtubuleassociated protein tau is regulated by protein phosphatase $2 \mathrm{~A}$ in mammalian brain. Implications for neurofibrillary degeneration in Alzheimer's disease. J Biol Chem. 2000; 275:5535-5544. [PubMed: 10681533]

13. Gong CX, Singh TJ, Grundke-Iqbal I, Iqbal K. Phospho-protein phosphatase activities in Alzheimer disease brain. J Neurochem. 1993; 61:921-927. [PubMed: 8395566]

14. Greenberg SG, Davies P. A preparation of Alzheimer paired helical filaments that displays distinct tau proteins by polyacrylamide gel electrophoresis. Proc Natl Acad Sci USA. 1990; 87:58275831. [PubMed: 2116006]

15. Grundke-Iqbal I, Iqbal K, Tung YC, Quinlan M, Wisniewski HM, Binder LI. Abnormal phosphorylation of the microtubule-associated protein tau (tau) in Alzheimer cytoskeletal pathology. Proc Natl Acad Sci USA. 1986; 83:4913-4917. [PubMed: 3088567]

16. Grundke-Iqbal I, Vorbrodt AW, Iqbal K, Tung YC, Wang GP, Wisniewski HM. Microtubuleassociated polypeptides tau are altered in Alzheimer paired helical filaments. Brain Res. 1988; 464:43-52. [PubMed: 3141008]

17. Hardy J, Selkoe DJ. The amyloid hypothesis of Alzheimer's disease: progress and problems on the road to therapeutics. Science. 2002; 297:353-356. [PubMed: 12130773]

18. Hasegawa M, Watanabe A, Takio K, et al. Characterization of two distinct monoclonal antibodies to paired helical filaments: further evidence for fetal-type phosphorylation of the tau in paired helical filaments. J Neurochem. 1993; 60:2068-2077. [PubMed: 7684067]

19. Hefti, F. Growth factors and neurodegeneration. In: Calne DB (ed) Neurodegenerative diseases. W.B. Saunders Company; Philadelphia: 1994. p. 177-194. 
20. Henckaerts E, Dutheil N, Zeltner N, et al. Site-specific integration of adeno-associated virus involves partial duplication of the target locus. Proc Natl Acad Sci USA. 2009; 106:7571-7576. [PubMed: 19372372]

21. Hitoshi S, Seaberg RM, Koscik C, et al. Primitive neural stem cells from the mammalian epiblast differentiate to definitive neural stem cells under the control of Notch signaling. Genes Dev. 2004; 18:1806-1811. [PubMed: 15289455]

22. Hock C, Heese K, Hulette C, Rosenberg C, Otten U. Region-specific neurotrophin imbalances in Alzheimer disease: decreased levels of brain-derived neurotrophic factor and increased levels of nerve growth factor in hippocampus and cortical areas. Arch Neurol. 2000; 57:846-851. [PubMed: 10867782]

23. Holzer M, Bruckner MK, Beck M, Bigl V, Arendt T. Modulation of APP processing and secretion by okadaic acid in primary guinea pig neurons. J Neural Transm. 2000; 107:451-461. [PubMed: 11215756]

24. Huang EJ, Reichardt LF. Trk receptors: roles in neuronal signal transduction. Annu Rev Biochem. 2003; 72:609-642. [PubMed: 12676795]

25. Iqbal K, Grundke-Iqbal I. Alzheimer neurofibrillary degeneration: significance, etiopathogenesis, therapeutics, and prevention. J. Cell. Mol. Med. 2008; 12:38-55. [PubMed: 18194444]

26. Iqbal K, Grundke-Iqbal I. Opportunities and challenges in developing Alzheimer disease therapeutics. Acta Neuropathol. 2011; 122:543-549. [PubMed: 21959585]

27. Kee N, Teixeira CM, Wang AH, Frankland PW. Preferential incorporation of adult-generated granule cells into spatial memory networks in the dentate gyrus. Nat Neurosci. 2007; 10:355-362. [PubMed: 17277773]

28. Kopke E, Tung YC, Shaikh S, Alonso AC, Iqbal K, Grundke-Iqbal I. Microtubule-associated protein tau abnormal phosphorylation of a non-paired helical filament pool in Alzheimer disease. J Biol Chem. 1993; 268:24374-24384. [PubMed: 8226987]

29. Korte M, Carroll P, Wolf E, Brem G, Thoenen H, Bonhoeffer T. Hippocampal long-term potentiation is impaired in mice lacking brain-derived neurotrophic factor. Proc Natl Acad Sci USA. 1995; 92:8856-8860. [PubMed: 7568031]

30. Lawlor PA, Bland RJ, Das P, et al. Novel rat Alzheimer's disease models based on AAV-mediated gene transfer to selectively increase hippocampal Abeta levels. Mol Neurodegener. 2007; 2:11. [PubMed: 17559680]

31. Li B, Yamamori H, Tatebayashi Y, et al. Failure of neuronal maturation in Alzheimer disease dentate gyrus. J Neuropathol Exp Neurol. 2008; 67:78-84. [PubMed: 18091557]

32. Li M, Guo H, Damuni Z. Purification and characterization of two potent heat-stable protein inhibitors of protein phosphatase 2A from bovine kidney. Biochemistry. 1995; 34:1988-1996. [PubMed: 7531497]

33. Liu F, Grundke-Iqbal I, Iqbal K, Gong CX. Contributions of protein phosphatases PP1, PP2A, PP2B and PP5 to the regulation of tau phosphorylation. Eur J Neurosci. 2005; 22:1942-1950. [PubMed: 16262633]

34. Liu R, Wang JZ. Protein phosphatase 2A in Alzheimer's disease. Pathophysiology. 2009; 16:273277. [PubMed: 19278841]

35. Lu B. BDNF and activity-dependent synaptic modulation. Learn Mem. 2003; 10:86-98. [PubMed: 12663747]

36. Madeira A, Pommet JM, Prochiantz A, Allinquant B. SET protein (TAF1beta, I2PP2A) is involved in neuronal apoptosis induced by an amyloid precursor protein cytoplasmic subdomain. FASEB J. 2005; 19:1905-1907. [PubMed: 16162853]

37. Malenka RC, Bear MF. LTP and LTD: an embarrassment of riches. Neuron. 2004; 44:5-21. [PubMed: 15450156]

38. Massa F, Koehl M, Wiesner T, et al. Conditional reduction of adult neurogenesis impairs bidirectional hippocampal synaptic plasticity. Proc Natl Acad Sci USA. 2011; 108:6644-6649. [PubMed: 21464314]

39. Minichiello L, Korte M, Wolfer D, et al. Essential role for TrkB receptors in hippocampusmediated learning. Neuron. 1999; 24:401-414. [PubMed: 10571233] 
40. Morris RG, Garrud P, Rawlins JN, O'Keefe J. Place navigation impaired in rats with hippocampal lesions. Nature. 1982; 297:681-683. [PubMed: 7088155]

41. Musumeci G, Sciarretta C, Rodriguez-Moreno A, et al. TrkB modulates fear learning and amygdalar synaptic plasticity by specific docking sites. J Neurosci. 2009; 29:10131-10143. [PubMed: 19675247]

42. Naslund J, Haroutunian V, Mohs R, et al. Correlation between elevated levels of amyloid betapeptide in the brain and cognitive decline. JAMA. 2000; 283:1571-1577. [PubMed: 10735393]

43. Oddo S, Caccamo A, Shepherd JD, et al. Triple-transgenic model of Alzheimer's disease with plaques and tangles: intra-cellular Abeta and synaptic dysfunction. Neuron. 2003; 39:409-421. [PubMed: 12895417]

44. Oddo S, Vasilevko V, Caccamo A, Kitazawa M, Cribbs DH, LaFerla FM. Reduction of soluble Abeta and tau, but not soluble Abeta alone, ameliorates cognitive decline in transgenic mice with plaques and tangles. J Biol Chem. 2006; 281:39413-39423. [PubMed: 17056594]

45. Phillips HS, Hains JM, Armanini M, Laramee GR, Johnson SA, Winslow JW. BDNF mRNA is decreased in the hippocampus of individuals with Alzheimer's disease. Neuron. 1991; 7:695-702. [PubMed: 1742020]

46. Qu D, Li Q, Lim HY, et al. The protein SET binds the neuronal Cdk5 activator p35nck5a and modulates Cdk5/ p35nck5a activity. J Biol Chem. 2002; 277:7324-7332. [PubMed: 11741927]

47. Rockenstein E, Adame A, Mante M, Moessler H, Windisch M, Masliah E. The neuroprotective effects of Cerebrolysin in a transgenic model of Alzheimer's disease are associated with improved behavioral performance. J Neural Transm. 2003; 110:1313-1327. [PubMed: 14628195]

48. Sairanen M, Lucas G, Ernfors P, Castren M, Castren E. Brain-derived neurotrophic factor and antidepressant drugs have different but coordinated effects on neuronal turnover, proliferation, and survival in the adult dentate gyrus. J Neurosci. 2005; 25:1089-1094. [PubMed: 15689544]

49. Seabrook GR, Ray WJ, Shearman M, Hutton M. Beyond amyloid: the next generation of Alzheimer's disease therapeutics. Mol Interv. 2007; 7:261-270. [PubMed: 17932415]

50. Selkoe DJ. Alzheimer's disease is a synaptic failure. Science. 2002; 298:789-791. [PubMed: 12399581]

51. Seo SB, McNamara P, Heo S, Turner A, Lane WS, Chakravarti D. Regulation of histone acetylation and transcription by INHAT, a human cellular complex containing the set oncoprotein. Cell. 2001; 104:119-130. [PubMed: 11163245]

52. Sontag E, Luangpirom A, Hladik C, et al. Altered expression levels of the protein phosphatase $2 \mathrm{~A}$ ABalphaC enzyme are associated with Alzheimer disease pathology. J Neuropathol Exp Neurol. 2004; 63:287-301. [PubMed: 15099019]

53. Steiner B, Wolf S, Kempermann G. Adult neurogenesis and neurodegenerative disease. Regen Med. 2006; 1:15-28. [PubMed: 17465817]

54. Stern Y, Albert S, Tang MX, Tsai WY. Rate of memory decline in AD is related to education and occupation: cognitive reserve? Neurology. 1999; 53:1942-1947. [PubMed: 10599762]

55. Sze CI, Troncoso JC, Kawas C, Mouton P, Price DL, Martin LJ. Loss of the presynaptic vesicle protein synaptophysin in hippocampus correlates with cognitive decline in Alzheimer disease. $\mathrm{J}$ Neuropathol Exp Neurol. 1997; 56:933-944. [PubMed: 9258263]

56. Tanaka J, Horiike Y, Matsuzaki M, Miyazaki T, Ellis-Davies GC, Kasai H. Protein synthesis and neurotrophin-dependent structural plasticity of single dendritic spines. Science. 2008; 319:16831687. [PubMed: 18309046]

57. Tanaka T, Zhong J, Iqbal K, Trenkner E, Grundke-Iqbal I. The regulation of phosphorylation of tau in SY5Y neuroblastoma cells: the role of protein phosphatases. FEBS Lett. 1998; 426:248-254. [PubMed: 9599018]

58. Tanimukai H, Grundke-Iqbal I, Iqbal K. Up-regulation of inhibitors of protein phosphatase-2A in Alzheimer's disease. Am J Pathol. 2005; 166:1761-1771. [PubMed: 15920161]

59. Tatebayashi Y, Lee MH, Li L, Iqbal K, Grundke-Iqbal I. The dentate gyrus neurogenesis: a therapeutic target for Alzheimer's disease. Acta Neuropathol (Berl). 2003; 105:225-232. [PubMed: 12557008] 
60. Terry RD, Masliah E, Salmon DP, et al. Physical basis of cognitive alterations in Alzheimer's disease: synapse loss is the major correlate of cognitive impairment. Ann Neurol. 1991; 30:572580. [PubMed: 1789684]

61. Tsujio I, Zaidi T, Xu J, Kotula L, Grundke-Iqbal I, Iqbal K. Inhibitors of protein phosphatase-2A from human brain: structures, immunocytological localization and activities towards dephosphorylation of the Alzheimer type hyperphosphorylated tau. FEBS Lett. 2005; 579:363372. [PubMed: 15642345]

62. Tyler WJ, Alonso M, Bramham CR, Pozzo-Miller LD. From acquisition to consolidation: on the role of brain-derived neurotrophic factor signaling in hippocampal-dependent learning. Learn Mem. 2002; 9:224-237. [PubMed: 12359832]

63. Vogelsberg-Ragaglia V, Schuck T, Trojanowski JQ, Lee VM. PP2A mRNA expression is quantitatively decreased in Alzheimer's disease hippocampus. Exp Neurol. 2001; 168:402-412. [PubMed: 11259128]

64. Voronkov M, Braithwaite SP, Stock JB. Phosphoprotein phosphatase 2A: a novel druggable target for Alzheimer's disease. Future Med Chem. 2011; 3:821-833. [PubMed: 21644827]

65. Wang JZ, Grundke-Iqbal I, Iqbal K. Kinases and phosphatases and tau sites involved in Alzheimer neurofibrillary degeneration. Eur J Neurosci. 2007; 25:59-68. [PubMed: 17241267]

66. Wang X, Blanchard J, Kohlbrenner E, et al. The carboxy-terminal fragment of inhibitor-2 of protein phosphatase-2A induces Alzheimer disease pathology and cognitive impairment. FASEB Journal. 2010; 24:4420-4432. [PubMed: 20651003]

67. West MJ, Slomianka L, Gundersen HJ. Unbiased stereological estimation of the total number of neurons in the subdivisions of the rat hippocampus using the optical fractionator. Anat Rec. 1991; 231:482-497. [PubMed: 1793176]

68. Winton MJ, Lee EB, Sun E, et al. Intraneuronal APP, not free Abeta peptides in 3×Tg-AD mice: implications for tau versus Abeta-mediated Alzheimer neurodegeneration. J Neurosci. 2011; 31:7691-7699. [PubMed: 21613482]

69. Xu B, Gottschalk W, Chow A, et al. The role of brain-derived neurotrophic factor receptors in the mature hippocampus: modulation of long-term potentiation through a presynaptic mechanism involving TrkB. J Neurosci. 2000; 20:6888-6897. [PubMed: 10995833]

70. Yamada K, Mizuno M, Nabeshima T. Role for brain-derived neurotrophic factor in learning and memory. Life Sci. 2002; 70:735-744. [PubMed: 11833737]

71. Yang P, Arnold SA, Habas A, Hetman M, Hagg T. Ciliary neurotrophic factor mediates dopamine D2 receptor-induced CNS neurogenesis in adult mice. J Neurosci. 2008; 28:2231-2241. [PubMed: 18305256]

72. Yoshiyama Y, Higuchi M, Zhang B, et al. Synapse loss and microglial activation precede tangles in a P301S tauopathy mouse model. Neuron. 2007; 53:337-351. [PubMed: 17270732]

73. Zhang X, Poo MM. Localized synaptic potentiation by BDNF requires local protein synthesis in the developing axon. Neuron. 2002; 36:675-688. [PubMed: 12441056]

74. Zhao C, Deng W, Gage FH. Mechanisms and functional implications of adult neurogenesis. Cell. 2008; 132:645-660. [PubMed: 18295581]

75. Zilka N, Filipcik P, Koson P, et al. Truncated tau from sporadic Alzheimer's disease suffices to drive neurofibrillary degeneration in vivo. FEBS Lett. 2006; 580:3582-3588. [PubMed: 16753151]

76. Zolotukhin S, Potter M, Zolotukhin I, et al. Production and purification of serotype 1, 2, and 5 recombinant adeno-associated viral vectors. Methods. 2002; 28:158-167. [PubMed: 12413414] 

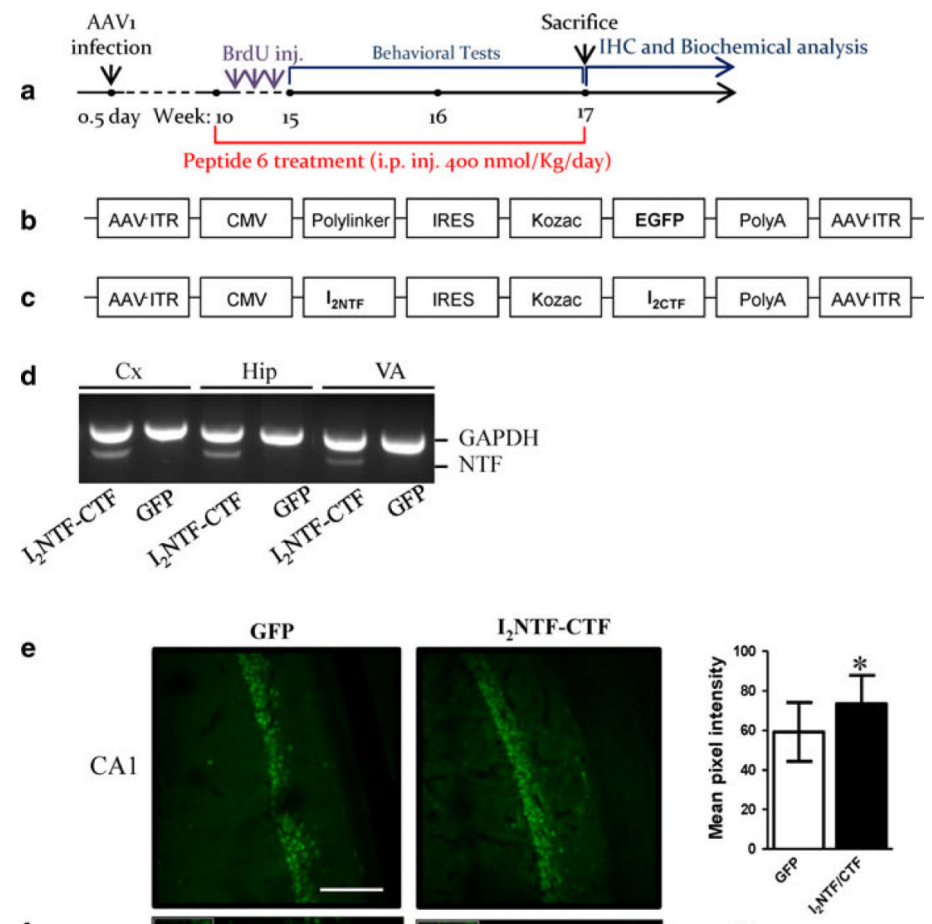

f
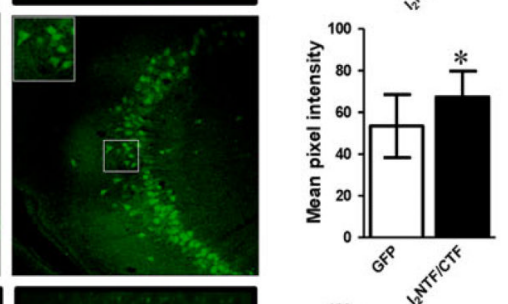

g
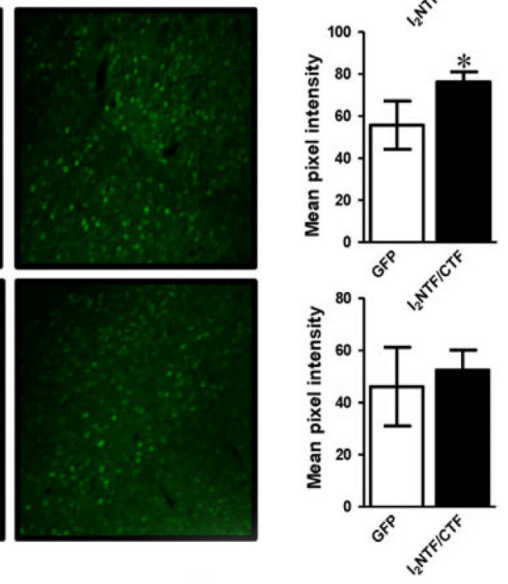

Fig. 1.

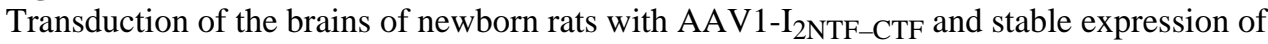
$\mathrm{I}_{2 \mathrm{NTF}}$ and $\mathrm{I}_{2 \mathrm{CTF}} 4$ months post-injection. a Schematic representation of the outline of the study. Linear maps of the AAV vector plasmids (based on pTRUF12). With the exception of the inverted terminal repeats (ITR) all viral genes had been removed and replaced with $\mathbf{b}$ GFP, or $\mathrm{c} \mathrm{I}_{2 \mathrm{NTF}}$ and $\mathrm{I}_{2 \mathrm{CTF}}$. $C M V$ cyglomegalovirus promoter, IRES internal ribosomal entry site from poliovirus. $\mathbf{d}$ mRNA expression of $\mathrm{I}_{2 \mathrm{NTF}}$, was detected by reverse-transcriptase polymerase chain reaction (rt-PCR) of RNA extracted from cortex (CX), hippocampus (Hip) and ventricular area (VA) of GFP and $\mathrm{I}_{2 \mathrm{NTF}-\mathrm{CTF}}$ rats and separated by agarose gel. $\mathbf{e}-\mathbf{h}$ Representative confocal images illustrating the expression of $\mathrm{I}_{2} \mathrm{PP} 2 \mathrm{~A}$ in GFP and $\mathrm{I}_{2 \mathrm{NTF}-\mathrm{CTF}}$ 
rats; the GFP auto fluorescence was negligible. Scale bar $100 \mu \mathrm{m}$. Quantification of $\mathrm{I}_{2} \mathrm{PP} 2 \mathrm{~A}$ staining fluorescence intensity in CA1 (e), CA3 (f) of the Hip, VA (g) and CX (h). Data are presented as mean \pm SD. $* p<0.05$ 
a
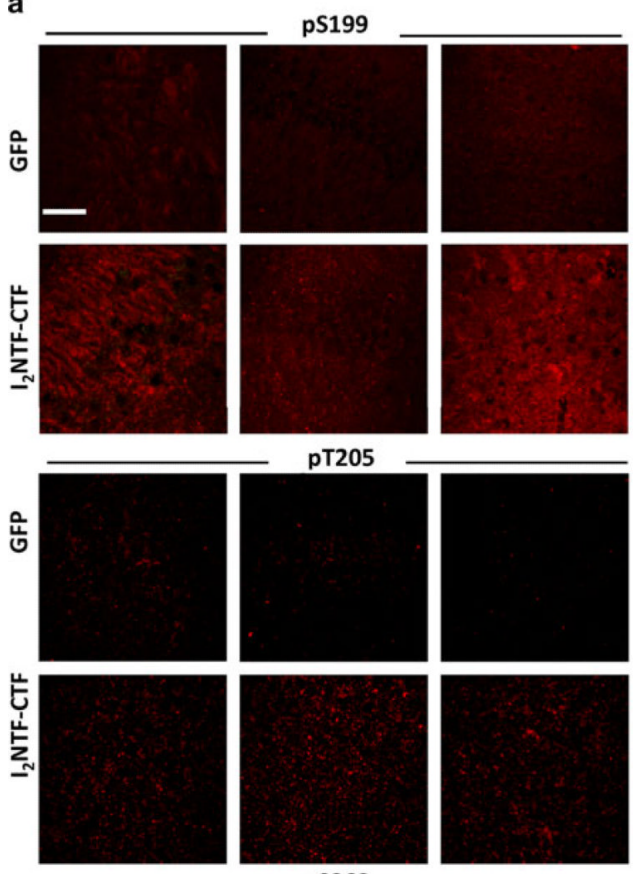

Fig. 2. b
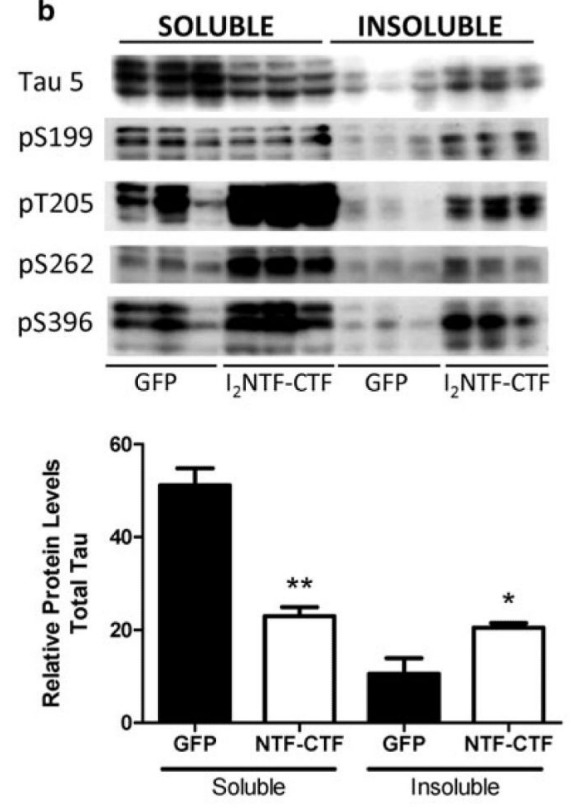

c GFP

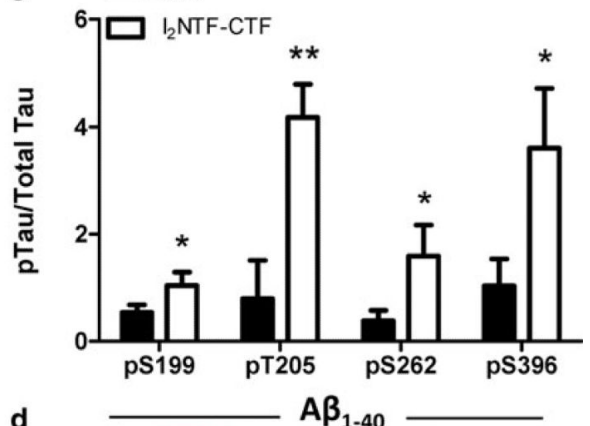

d
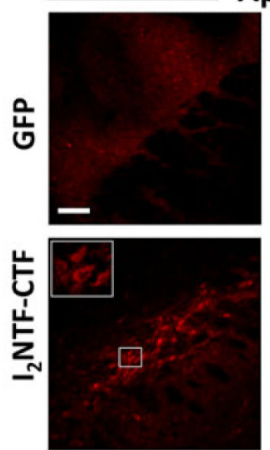

LV

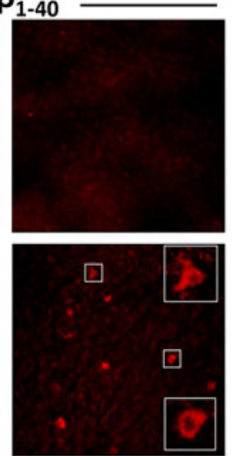

CX

$\mathrm{I}_{2 \mathrm{NTF}-\mathrm{CTF}}$ rats at 13 months of age show increase in abnormal hyperphosphorylation and aggregation of tau and intraneuronal $\mathrm{A} \beta$. a Immunohistochemical staining with anti-tau pSer199, pThr205, pSer262, and pSer396 in CA3 and CA1 areas of the hippocampus and in the cerebral cortex $(\mathrm{CX})$ in $\mathrm{I}_{2 \mathrm{NTF}-\mathrm{CTF}}$ and GFP control rats. b Western blots and quantitation of sarkosyl-soluble and sarkosyl-insoluble fractions from the cerebral cortices of $\mathrm{I}_{2 \mathrm{NTF}-\mathrm{CTF}}$ and GFP rats developed with a pan tau antibody Tau 5 and phosphotau antibodies pSer199, pThr205, pSer262, and pSer396. c Abnormal hyperphosphorylation of tau (ptau/total tau) determined by quantitation of Western blots from the cerebral cortices of 
$\mathrm{I}_{2 \mathrm{NTF}-\mathrm{CTF}}$ and GFP rats. $\mathbf{d}$ Immunohistochemical staining with anti-A $\beta_{40}$ (Invitrogen) of the lateral ventricle (LV) area and the cerebral cortex (CX) in $\mathrm{I}_{2 \mathrm{NTF}-\mathrm{CTF}}$ and GFP rats. Insets show intraneuronal A $\beta$. Magnification bar in a $50 \mu \mathrm{m}, \mathbf{d} 100 \mu \mathrm{m} .{ }^{*} p<0.05 ; * * p<0.01$ 

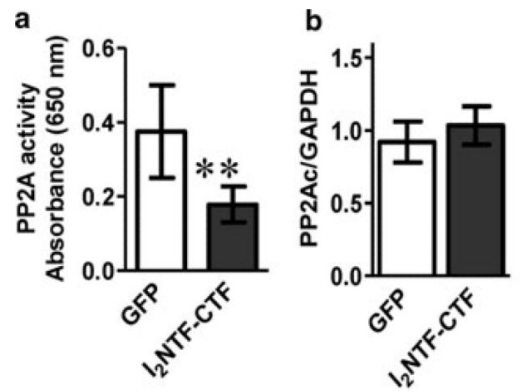

C

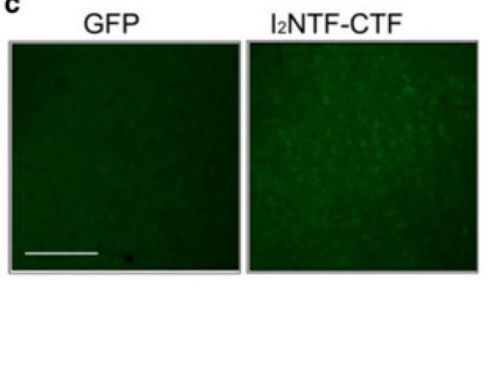

d

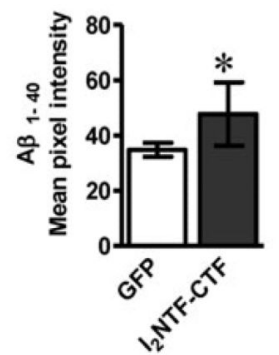

e
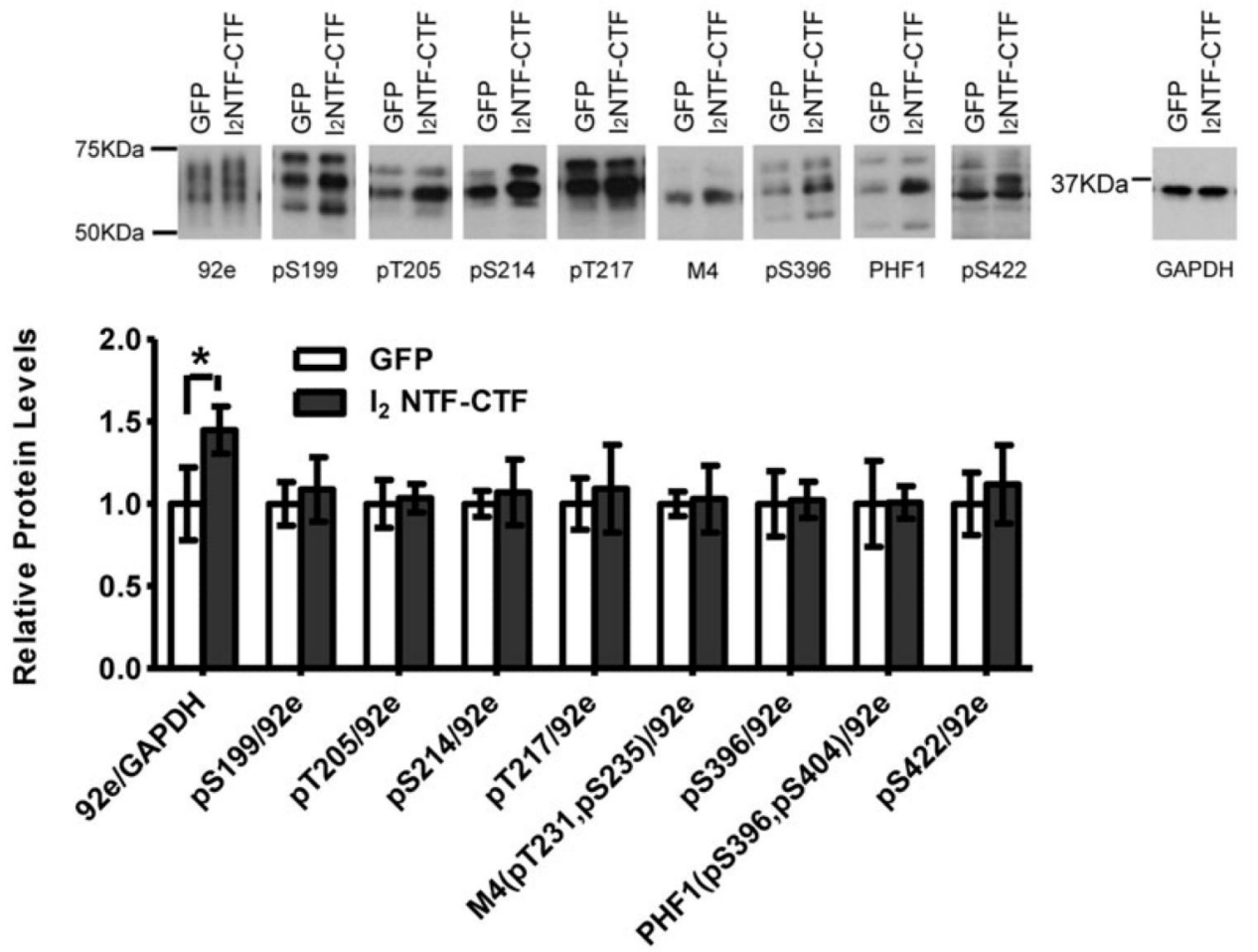

f

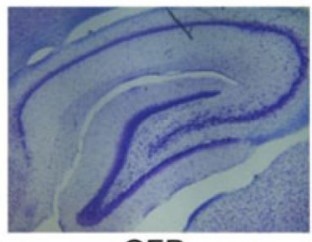

GFP

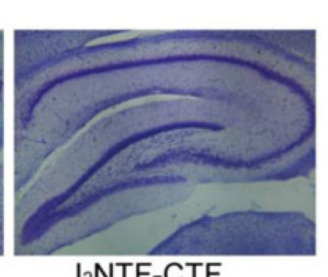

$\mathrm{I}_{2} \mathrm{NTF}-\mathrm{CTF}$
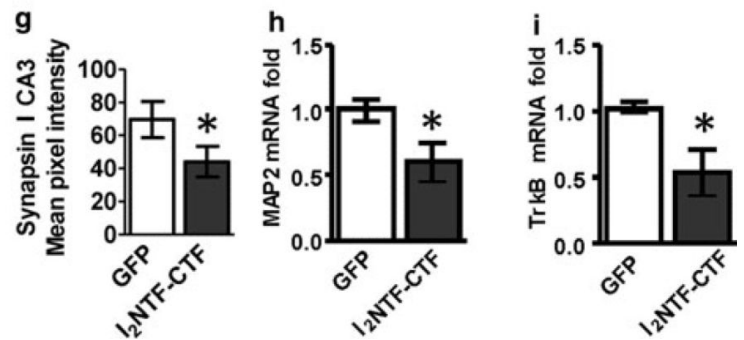

Fig. 3.

Reduced PP2A activity, accumulation of $A \beta_{1-40}$ and tau, and loss of neuronal plasticity in $\mathrm{I}_{2 \mathrm{NTF}-\mathrm{CTF}}$ rats. a PP2A activity in hippocampus extract of 4-month-old rats. b PP2A catalytic subunit (PP2Ac) level assayed by Western blots in hippocampus homogenate. c Representative photomicrographs and $\mathbf{d}$ semi-quantitative expression level of $\mathrm{A} \beta_{1-40}$ in the cortex of GFP and I INTF-CTF rats. e Representative Western blots developed with phosphospecific tau antibodies. Quantification of total tau, and hyperphosphorylation of tau at pSer199, pThr205, pSer214, pThr217, pThr231/pSer235, pSer396, pSer396/pSer404, and pSer422. Quantification of Western blots is shown as \pm SD, normalized by GAPDH for total 
tau and for all the phosphorylation sites by total tau. $\mathbf{f}$ Images of Nissl staining of hippocampus from GFP and $\mathrm{I}_{2 \mathrm{NTF}-\mathrm{CTF}}$ rats. $\mathbf{g}$ Expression level of synapsin I in CA3 of the hippocampus detected by immunohistochemistry. $\mathbf{h}$ mRNA expression level of MAP2, quantified by RT- $q$ PCR, in cortex form GFP and $\mathrm{I}_{2 \mathrm{NTF}-\mathrm{CTF}}$ rats. i mRNA expression level of TrkB receptor, quantified by RT- $q$ PCR, in cortex form GFP and $\mathrm{I}_{2 \mathrm{NTF}-\mathrm{CTF}}$ rats. ${ }^{*} p<0.05$ 

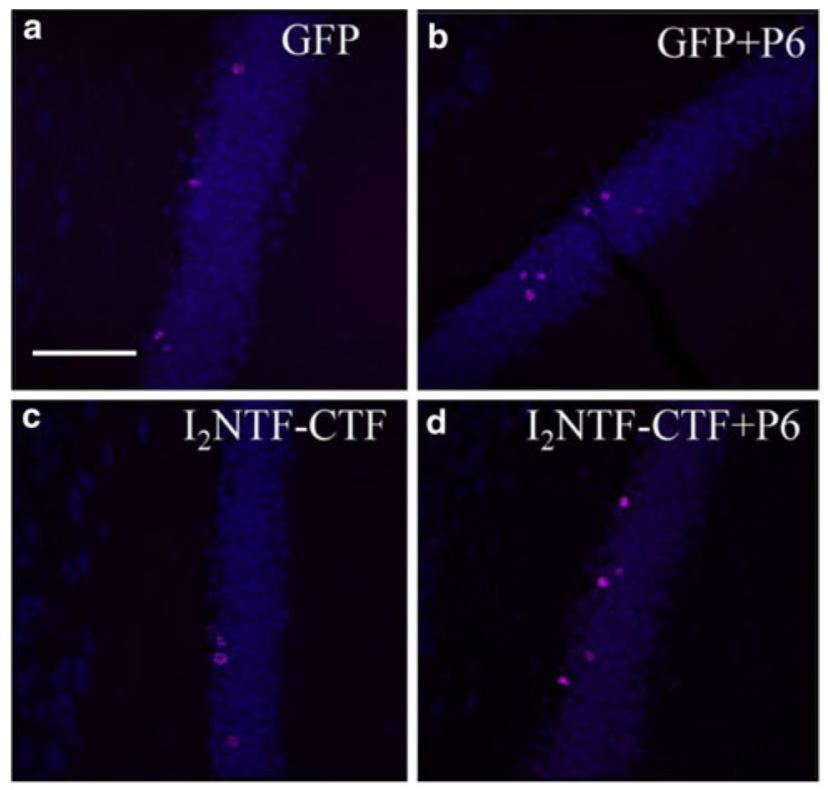

e

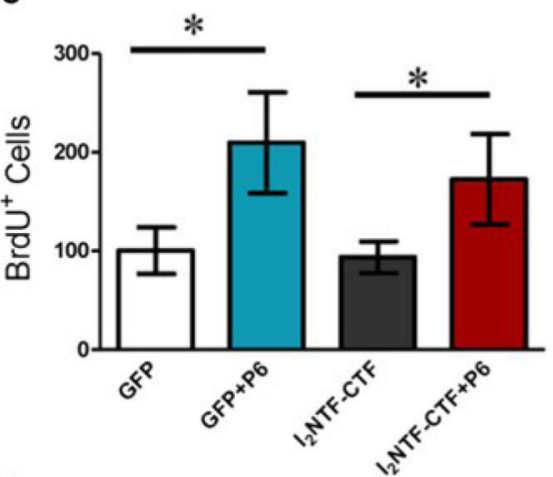

g

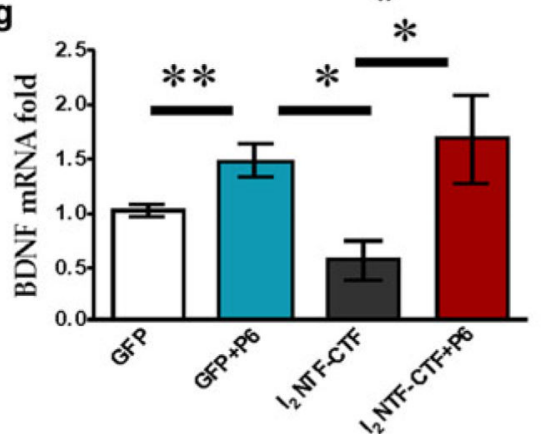

f

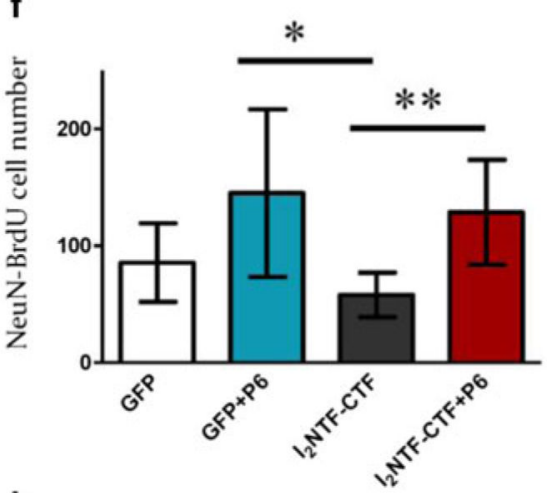

h

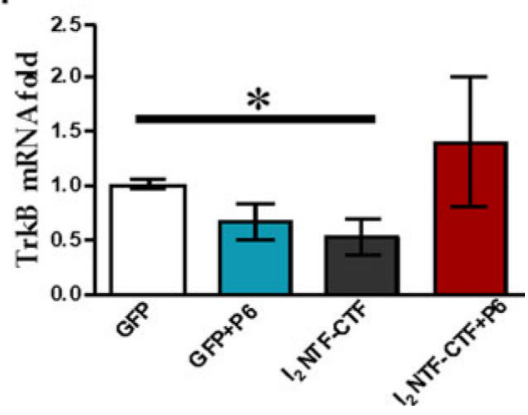

Fig. 4.

Peptide 6-induced increase in neurogenesis in $\mathrm{I}_{2 \mathrm{NTF}-\mathrm{CTF}}$ and GFP rats. (a-d)

Photomicrographs illustrating expression of BrdU- (red) and NeuN-positive cells (blue). Scale bar $20 \mu \mathrm{m}$. e Quantification of BrdU-positive cells in the iGCL of the DG. f Colocalization of BrdU-NeuN-IR cells in the SGZ. $\mathbf{g}$ mRNA expression level of BDNF and $\mathbf{h}$ TrkB receptor, quantified by RT- $q$ PCR, in cortex from GFP and $\mathrm{I}_{2 \mathrm{NTF}-\mathrm{CTF}}$ rats treated with Peptide 6 (P6) or vehicle only. Data are expressed as the fold difference compared with vehicle-treated GFP animals. ${ }^{*} p<0.05,{ }^{* *} p<0.01$ 
a

它它

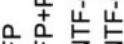

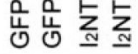
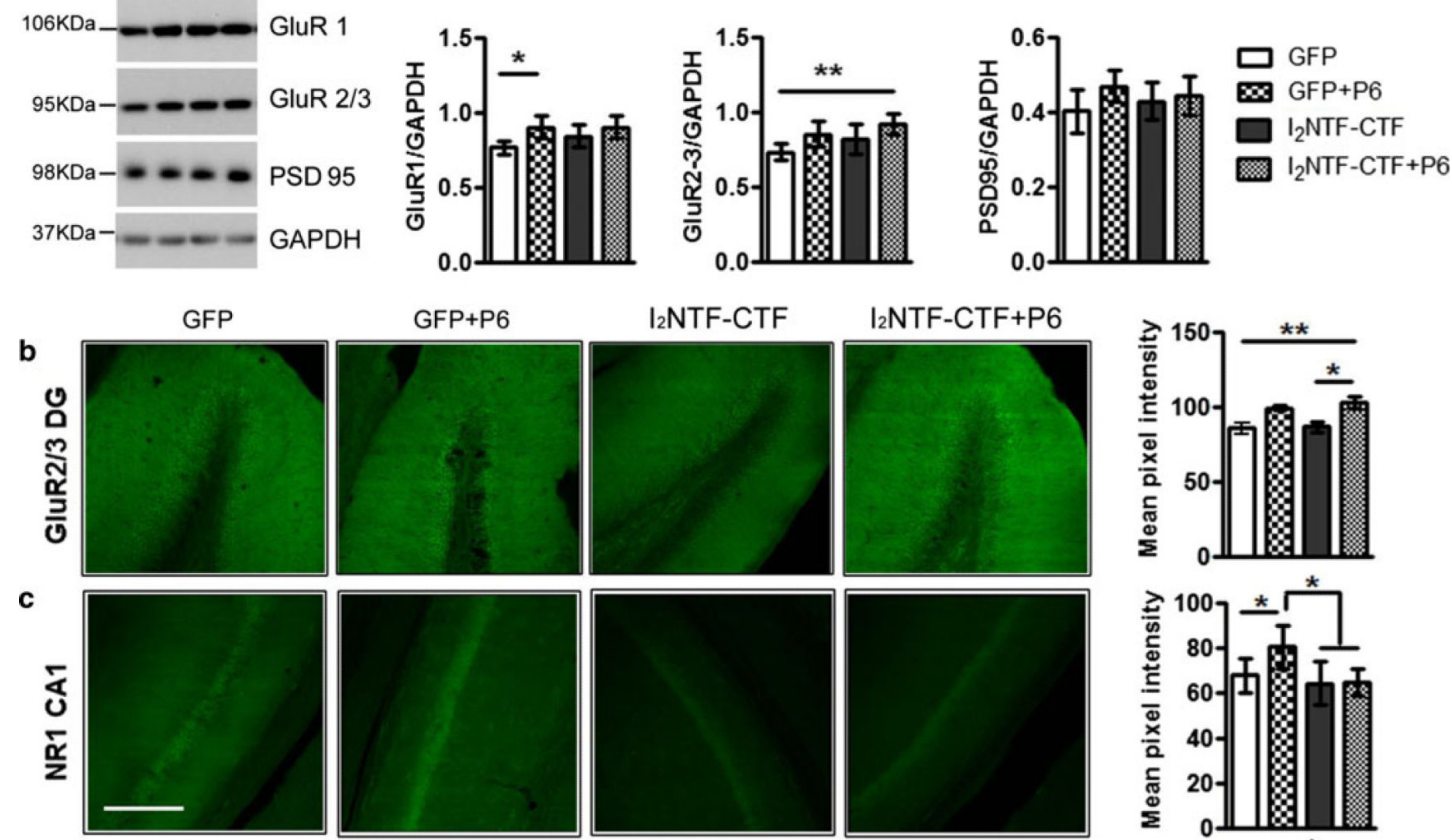

d
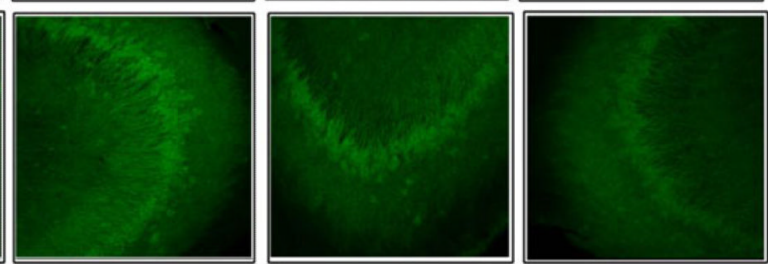

e
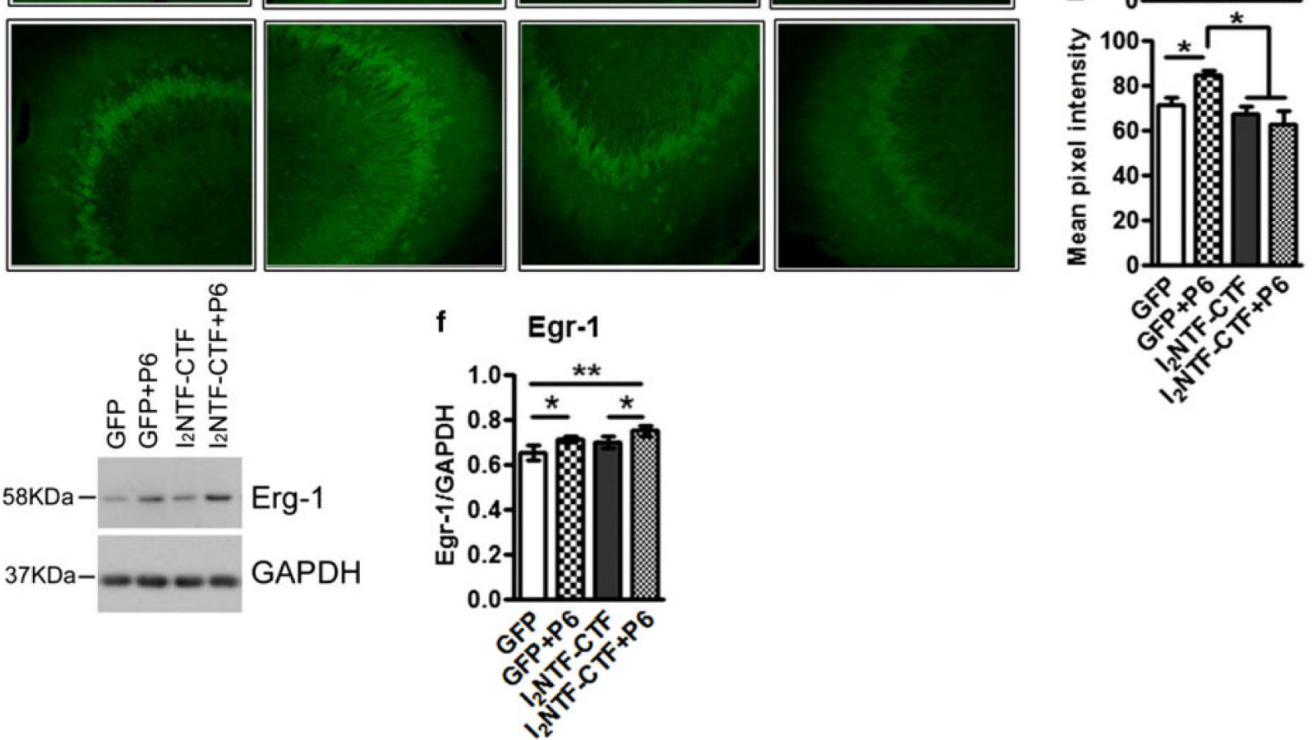

Fig. 5.

Peptide 6 (P6)-induced increase in glutamate receptor levels. a Representative immunoblots and relative quantification in the whole hippocampus of GluR1, GluR2-3 and PSD-95.

Representative photomicrographs and semi-quantitative expression level of GluR2/3 in DG (b), NR1 in CA1 (c), and CA3 (d). Scale bar $100 \mu \mathrm{m}$. e Representative Western blots and relative quantification of Egr-1 normalized against GAPDH in hippocampus homogenate. * $p$ $<0.05, * * p<0.01$ 
a

GFP

GFP+P6
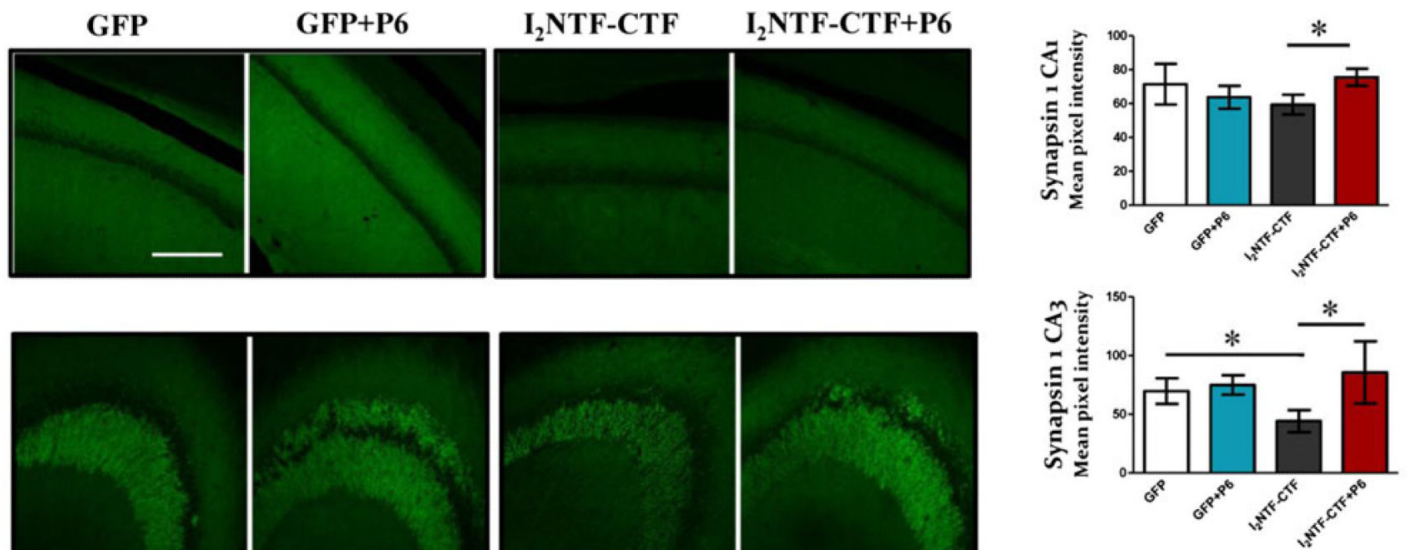

b
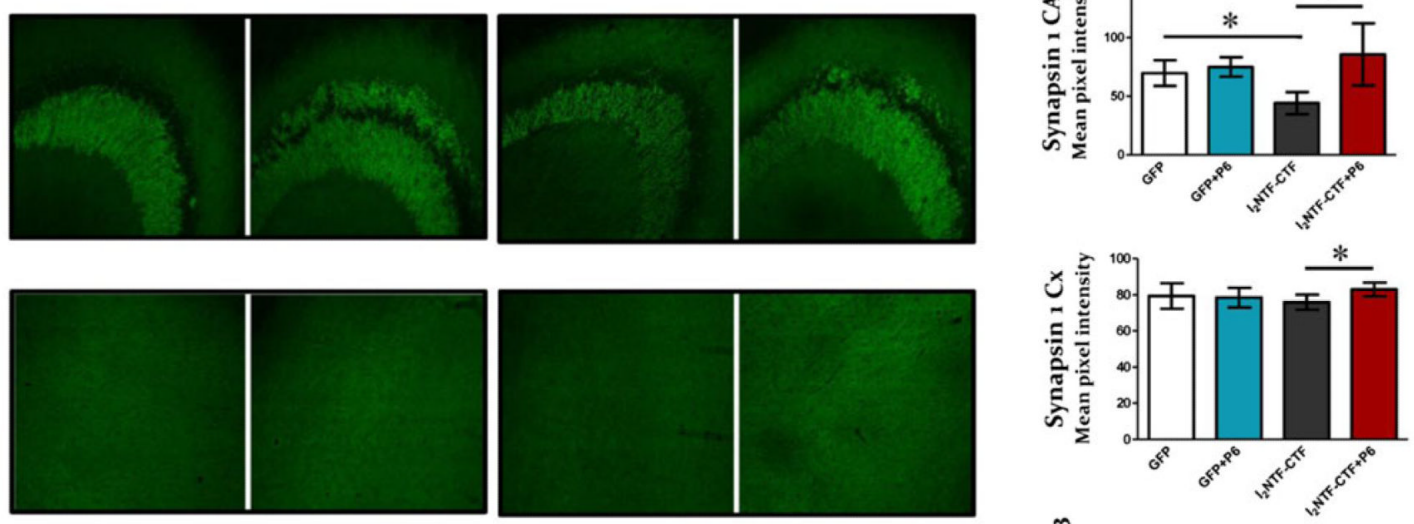

c
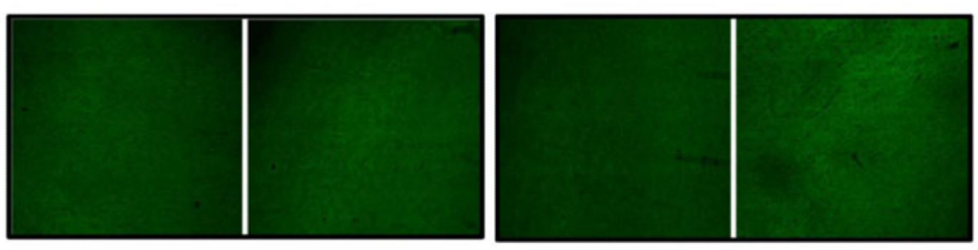

d
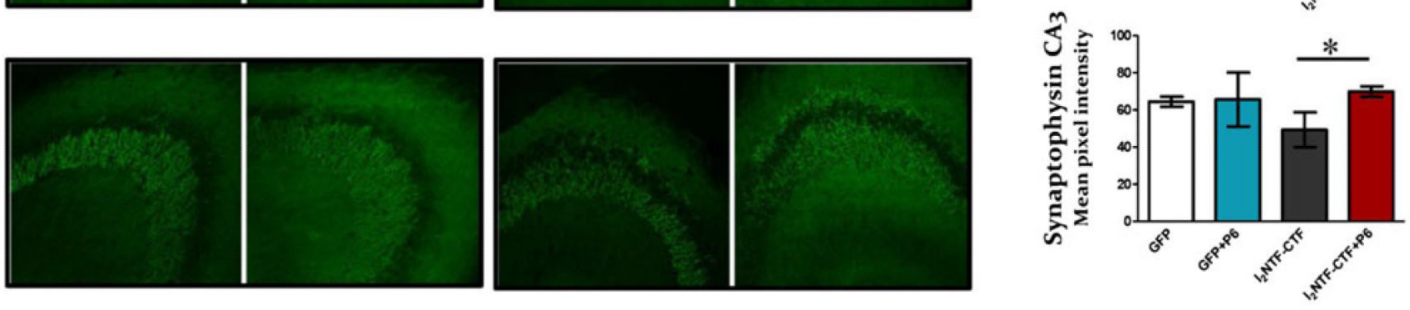

e
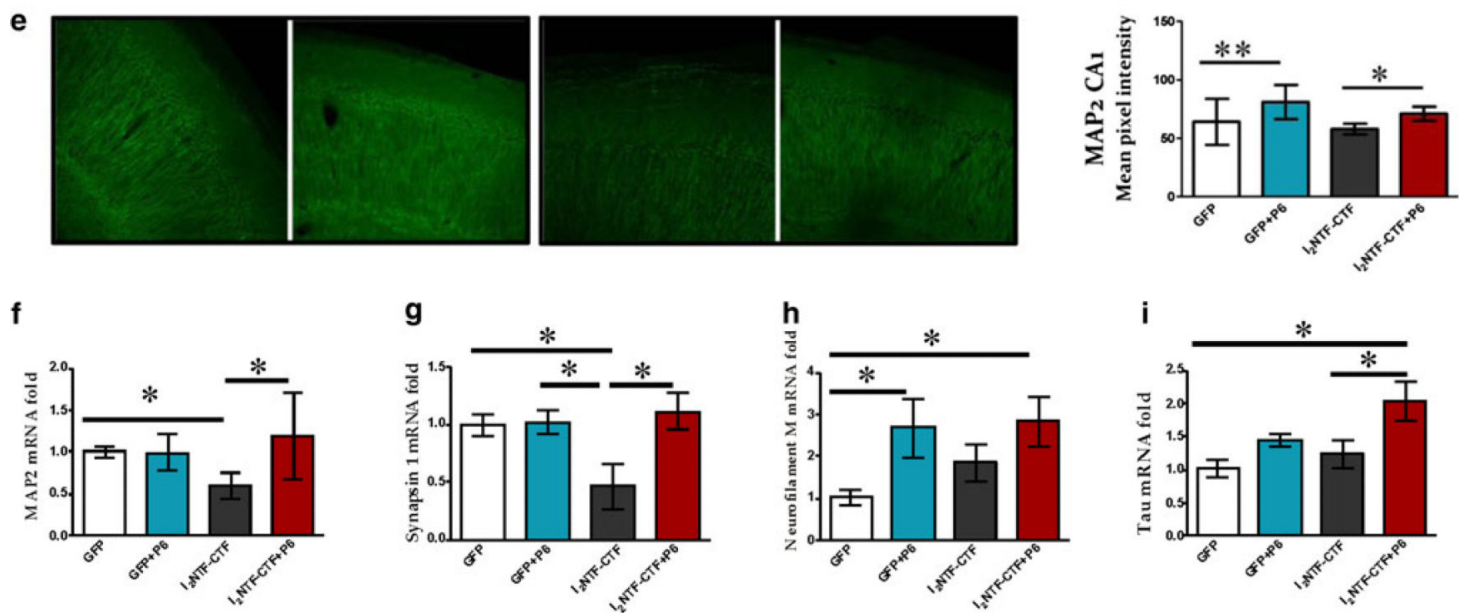

Fig. 6.

Peptide 6 (P6)-induced increase in dendritic and synaptic plasticity. Representative photomicrographs and semi-quantitative expression level of synapsin I in CA1 (a), CA3 (b) and cortex (c), synaptophysin in CA3 (d), and MAP2 in CA1 (e). Scale bar $100 \mu \mathrm{m}$. mRNA expression level of MAP2 (f), synapsin I (g), neurofilament M (h) and tau (i) quantified by RT- $q$ PCR in cortex. $* p<0.05, * * p<0.01$ 
a
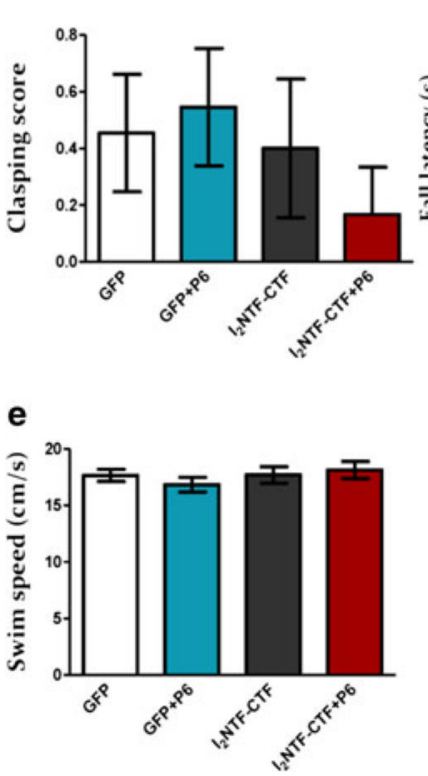

b

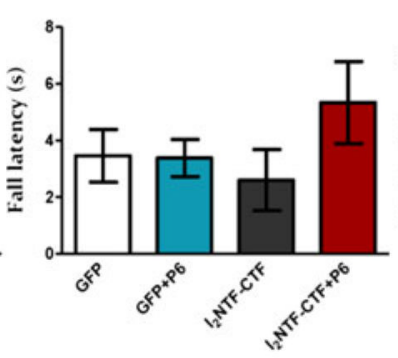

f

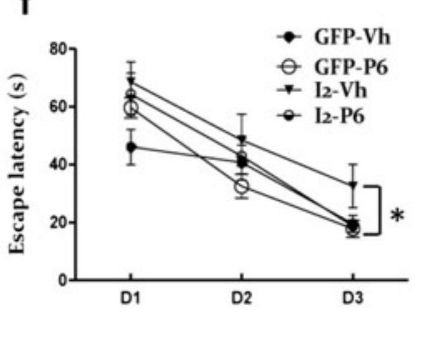

C
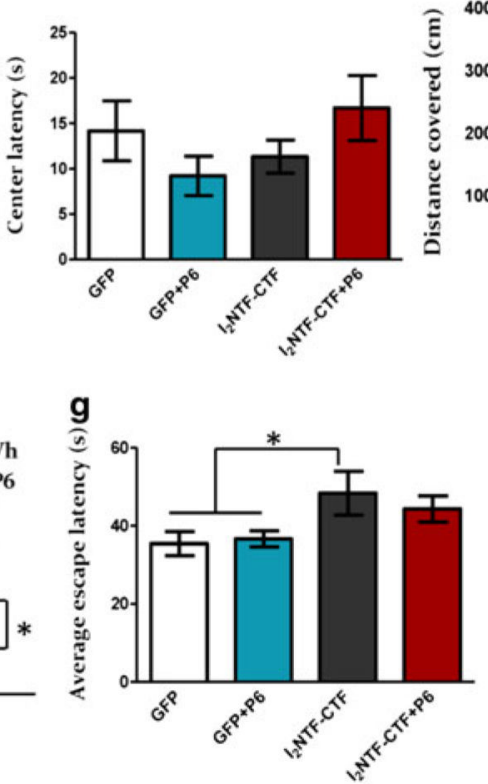

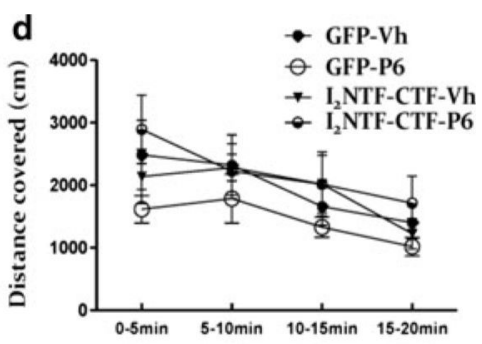

h

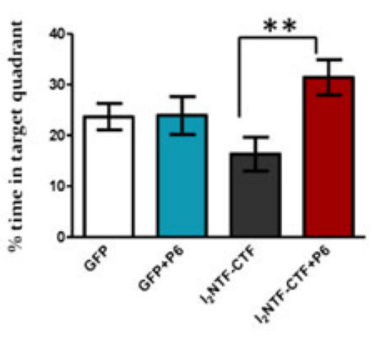

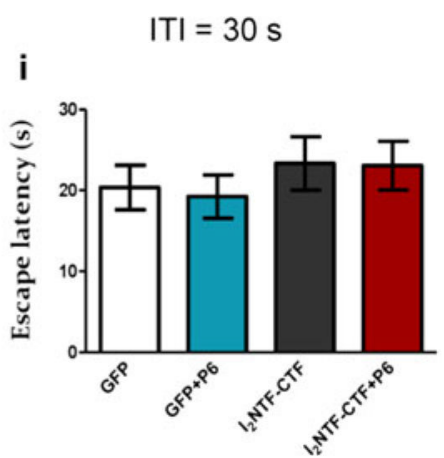
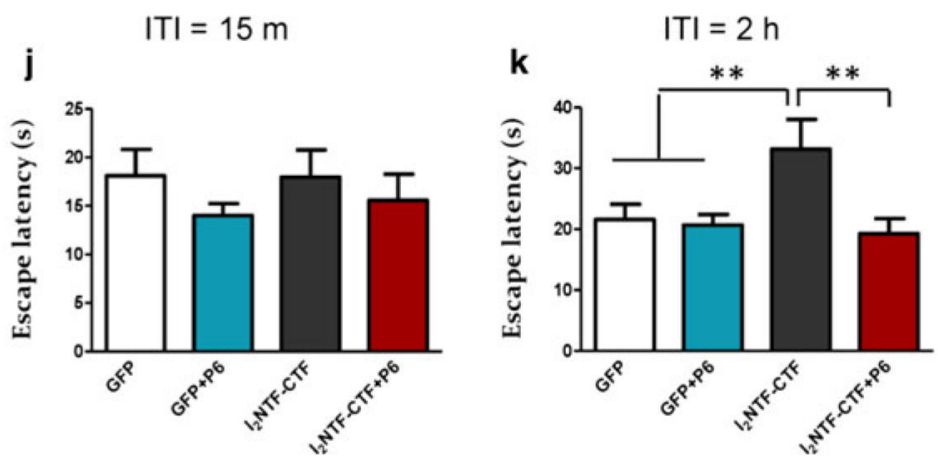

Fig. 7.

Treatment with Peptide 6 (P6) rescued cognitive impairments in $\mathrm{I}_{2 \mathrm{NTF}-\mathrm{CTF}}$ rats. (a-d) General behavior. a Clasping reflex. b Prehensile traction test. c Anxiety in the open field. d Exploration in the open field. e-h Spatial reference memory task. e Swim speed. f Learning performance across training. $\mathbf{g}$ Training performance, average escape latencies. $\mathbf{h}$ Probe trial, $\%$ of time spent in the target quadrant. i-k Working memory task. i Day 1 inter-trial intervals (ITI) $30 \mathrm{~s}$. j Day 2 ITI 15 min. k Day 3 ITI $2 \mathrm{~h}$ 